\title{
DEFORMATION CHARACTERISTICS OF DRY HOSTUN SAND WITH PRINCIPAL STRESS AXES ROTATION
}

\author{
M. Blanci ${ }^{\text {i) }}$ H. Di BenedetTo ${ }^{\text {ii) }}$ and S. TIOUAJNi ${ }^{\text {iii) }}$
}

\begin{abstract}
Coaxiality between the principal directions of the stress tensor and the principal directions of the plastic strain increment tensor is assumed in conventional plasticity models. In order to investigate coaxiality, or non-coaxiality, between these two principal directions, a series of drained tests on dry Hostun sand was carried out using a precision Hollow Cylinder Apparatus (HCA). The applied stress path includes large Principal Stress Axes Rotation (PSAR). Two of the three principal stresses are kept constant. Therefore, among the three principal stresses, only the intermediate principal stress, which is confining pressure (same pressure outside the hollow cylinder for internal and external lateral surfaces), changes during loading. During these tests, at different stress levels, elastic (or quasi-elastic) properties are also investigated, using small amplitude quasi-static cycles. These small cycles are performed in two different directions by successively changing only the axial stress $\sigma_{z z}$ or the shear stress $\sigma_{\theta z}$. Elastic experimental properties are well simulated using the DI Bendetto-Geoffroy-Sauzeat (DBGS) hypo-elastic model, which takes into account PSAR. For each test, the elastic part of deformation is calculated using the DBGS model and removed from global strain so that it is possible to to focus only on the irreversible part (plastic part). Then, the principal directions of stress and plastic strain increment are compared. Experimental results show that there is no coaxiality between these directions. This observation attests to the existence of a non-coaxial plasticity. In addition, the coupling between tge coaxial and non-coaxial part is clearly shown. Experimental results reveal that the plastic strain part is very important for the first large amplitude cycles and remains greater than the elastic part even after 20 cycles.
\end{abstract}

Key words: deformation, drained shear, elasticity, laboratory test, plasticity, repeated loads, sand, torsion, yield (IGC: D6)

\section{INTRODUCTION}

The focus on the deformation characteristics of sandy grounds over the last four decades has been especially important in that it has provided a framework for investigating settlement and liquefaction during earthquakes. During this time, the effects of cyclic loading have been taken into account very carefully (Tastusoka and Ishihara, 1974). These conditions may take place with the continuous rotation of the principal stress axes (Ishihara and Towhata, 1983). Principal Stress Axes Rotation (PSAR) is also a current loading path, which has an important impact on geotechnical constructions (Jardine, 1994). Elastic and plastic deformations are dependent on the rotation of principal stress axes. For these reasons, PSAR effects need to be studied and modelled correctly. The reproduction of PSAR conditions in a laboratory requires complex devices. Different campaigns used Hollow Cylinder Apparatuses (HCA) to test sand samples (Ishihara and Towhata, 1983, Miura et al., 1986, Pradel et al.,
1990 and Gutierrez et al., 1991, among others). These studies show a difference between the principal directions of stress and the plastic strain increment. This means that the standard elasto-plastic hypothesis of coaxiality is not relevant. There is a non-coaxial plastic behaviour.

Non-coaxiality has been often studied in order to explain shear band formation in the strain hardening region. Rudnicki and Rice (1975), Tsutsumi and Hashiguchi (2005), Yu and Yuan (2006) and Yu (2006) developed non-coaxial models in a two dimensional stress plan. Recently, Qian et al. (2008) extended these models in a general three dimensional tensorial space. Non-coaxial plastic models also allow for a better understanding of some sand characteristics. For example, Gutierrez and Ishihara (2000) performed a better evaluation of energy dissipation thanks to non-coaxiality.

In this article, the authors propose to study the influence of PSAR on both elastic and plastic deformations. An experimental campaign on drained dry Hostun sand using large amplitude cyclic loadings with a continu-

i) Researcher, Physical Modelling in Geotechnics Group, GER, IFSTTAR, LUNAM University, France (formerly PhD Student, Ecole Nationale des Travaux Publics de l’Etat, University of Lyon) (matthieu.blanc@ifsttar.fr).

ii) Professor, Département Génie Civil et Bâtiment (CNRS 3237), Ecole Nationale des Travaux Publics de l'Etat, University of Lyon, France.

iii) $\mathrm{PhD}$ Student, ditto.

The manuscript for this paper was received for review on June 18, 2010; approved on March 31, 2011.

Written discussions on this paper should be submitted before May 1, 2012 to the Japanese Geotechnical Society, 4-38-2, Sengoku, Bunkyo-ku, Tokyo 112-0011, Japan. Upon request the closing date may be extended one month. 
ous rotation of the principal stress axes was conducted. The HCA, developed at the Ecole Nationale des Travaux Publics de l'Etat (ENTPE) laboratory and named "T4C StaDy," has the same outside pressure for the internal and external lateral surfaces. This choice has the advantage of creating homogenous stress and strain fields within the sample. However, only the two extreme principal stresses can be kept constant during the rotation, while the intermediate one, $\sigma_{2}=\sigma_{\mathrm{rr}}$, changes. Therefore, peculiar analyses have to be introduced. Di Benedetto et al. (2001) showed the importance of PSAR on the evolution of elastic deformation. An elastic investigation was also conducted using small amplitude quasi-static cyclic loadings in different directions.

The "T4C StaDy" HCA is described at first. Then, the test procedure is introduced and the test results are exposed. A general hypo-elastic model (developed within the laboratory and named DBGS) is presented; simulations carried out with this model are compared with experimental measurements, revealing a non-negligible part of non-coaxial elastic deformation. This elastic simulated strain is removed from the total strain to obtain the plastic part. The general decomposition in the coaxial and non-coaxial part of different tensors is exposed. Then the amplitudes of the total and non-coaxial plastic strain increments are compared. Finally, this evolution is studied with a number of large cycles to investigate the cyclic hardening properties.

\section{HOLLOW CYLINDRICAL APPARATUS "T4C STADY"}

The hollow cylinder sample in the HCA "T4C StaDy" (Fig. 1) has a height of $12 \mathrm{~cm}$, an outer diameter of $20 \mathrm{~cm}$ and an inner diameter of $16 \mathrm{~cm}$. A numerical analysis of stress and strain distributions in the HCA (Hight et al.,

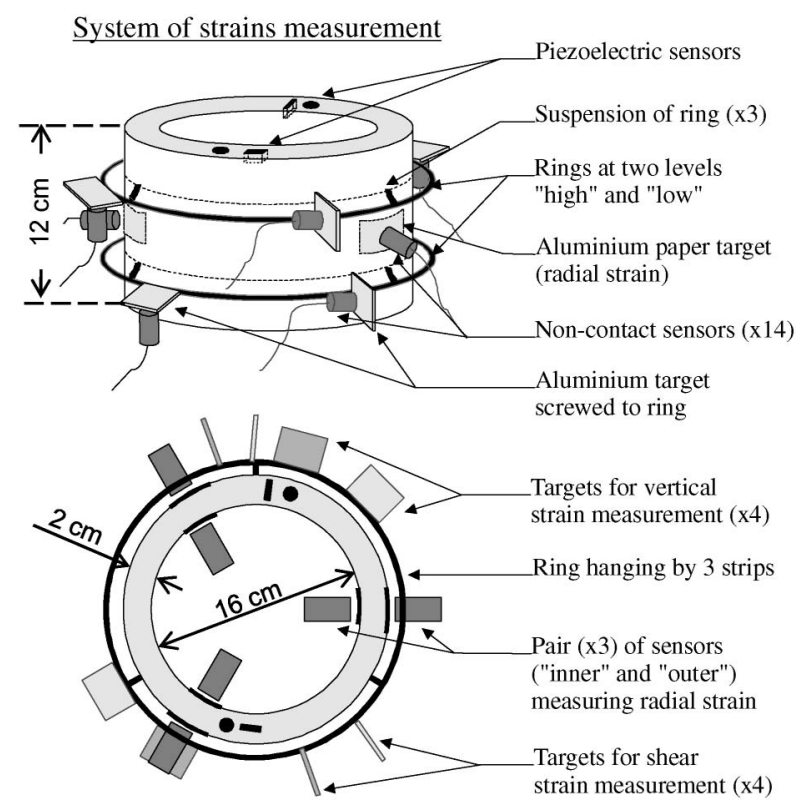

Fig. 1. Schematic view of the HCA "T4C StaDy"
1983) shows that these dimensions allow for reasonable homogeneity of stress and strain tensors within the sample. Equations used for the calculation of homogenous stress and strain tensor are given in Sauzeat (2003). Two neoprene membranes $(0.5 \mathrm{~mm}$ thickness $)$ constitute the lateral sides, while two rigid platens close the sample at the top and the bottom. The top cap, connected to the press piston, is mobile in rotation and axial translation. Axial and torsional loading is ensured by a servo-controlled hydraulic press. Axial and shear load cells are incorporated in the piston. Measurements accuracies of axial and shear stresses can be respectively estimated equal to $0.1 \mathrm{kPa}$ and $0.05 \mathrm{kPa}$ (Duttine, 2005). The lateral sides (both internal and external) of the sample are subjected to atmospheric pressure while vacuum pressure down to $20 \mathrm{kPa}$ is applied inside the sample. This pressure is controlled by an electronic vacuum regulator from an electronic signal input. Stress state of the hollow cylindrical sample is presented in Fig. 2. The stress tensor is given in Eq. (1) in $\left(\vec{e}_{\mathrm{r}}, \vec{e}_{\theta}, \vec{e}_{\mathrm{z}}\right)$ sample axes:

$$
\sigma_{(\mathrm{r} \theta \mathrm{z})}=\left(\begin{array}{ccc}
\sigma_{\mathrm{rr}} & 0 & 0 \\
0 & \sigma_{\theta \theta} & \sigma_{\theta \mathrm{z}} \\
0 & \sigma_{\theta \mathrm{z}} & \sigma_{\mathrm{zz}}
\end{array}\right)=\left(\begin{array}{ccc}
P_{\mathrm{c}} & 0 & 0 \\
0 & P_{\mathrm{c}} & \tau \\
0 & \tau & P_{\mathrm{c}}+\sigma_{\mathrm{a}}
\end{array}\right)
$$

with $P_{\mathrm{c}}$ confining pressure, $\sigma_{\mathrm{a}}$ axial stress minus orthoradial stress $\left(=\sigma_{\mathrm{zz}}-\sigma_{\theta \theta}\right)$ (Fig. 3) and $\tau$ shear stress in the $\left(\vec{e}_{\theta}, \vec{e}_{\mathrm{z}}\right)$ directions.

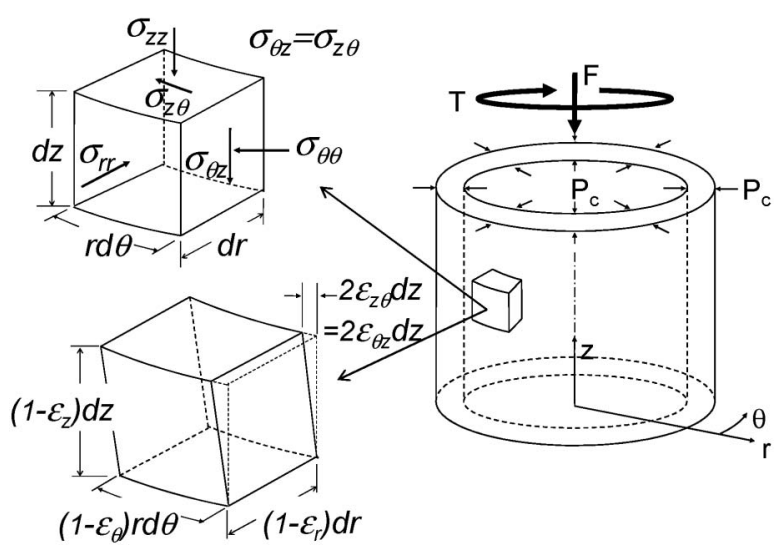

Fig. 2. Applied loads in a hollow cylindrical sample-Idealized stresses and strains on an element

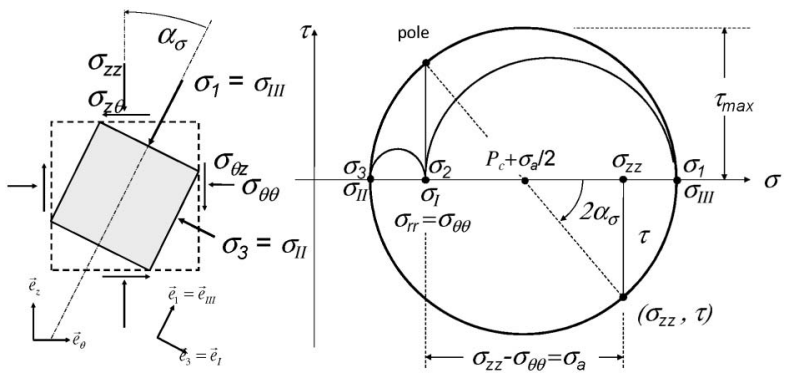

Fig. 3. Analysis of stress state: principal stresses-definition of angle $\alpha_{\sigma}$ of major principal stress direction in $\left(\vec{e}_{\theta}, \vec{e}_{z}\right)$ axes (left) and Mohr's circle representation (right) 
The accurate local systems of strain measurement (Fig. 1) include 14 non contact transducers. Vertical and angular displacements are measured on two levels thanks to two light duralumin rings less than $30 \mathrm{~g}$ in weight, which are hung on 3 points of the outer membrane. Rings have aluminum targets at which the non-contact transducers are aimed (8). Radial displacements (outer and inner) are also measured by a set of non-contact transducers (6) pointing through the membranes towards aluminum foils placed inside the membranes in contact with sand. To insure better accuracy, all non-contact transducers $(1 \mathrm{~mm}$ or $2 \mathrm{~mm}$ range) can be moved manually by micrometric screws during the test. The resulting estimated strain accuracy is better than $0.0005 \%$ (Duttine, 2005). However, as an obvious counterpart, the transducers need to be repositioned during testing. The form of the strain tensor in the sample axes $\left(\vec{e}_{\mathrm{r}}, \vec{e}_{\theta}, \vec{e}_{\mathrm{z}}\right)$ is given in Eq. (2) and the terms of the strain tensor are represented in Fig. 2.

$$
\varepsilon_{(\mathrm{r} \theta \mathrm{z})}=\left(\begin{array}{ccc}
\varepsilon_{\mathrm{r}} & 0 & 0 \\
0 & \varepsilon_{\theta} & \gamma / 2 \\
0 & \gamma / 2 & \varepsilon_{\mathrm{z}}
\end{array}\right)
$$

\section{Principal Stress Convention and PSAR Angle}

Major $\sigma_{1}$, Intermediate $\sigma_{2}$ and Minor $\sigma_{3}$ principal stresses can be expressed with $P_{\mathrm{c}}, \sigma_{\mathrm{a}}$ and $\tau$ :

$$
\left\{\begin{array}{l}
\sigma_{1}=\sigma_{\mathrm{III}}=P_{\mathrm{c}}+\frac{\sigma_{\mathrm{a}}}{2}+\frac{\sqrt{\sigma_{\mathrm{a}}^{2}+4 \tau^{2}}}{2} \\
\sigma_{2}=\sigma_{\mathrm{I}}=P_{\mathrm{c}} \\
\sigma_{3}=\sigma_{\mathrm{II}}=P_{\mathrm{c}}+\frac{\sigma_{\mathrm{a}}}{2}-\frac{\sqrt{\sigma_{\mathrm{a}}^{2}+4 \tau^{2}}}{2}
\end{array}\right.
$$

Principal directions $\left(\vec{e}_{1}, \vec{e}_{2}, \vec{e}_{3}\right)$ are associated to principal stresses $\left(\sigma_{1}, \sigma_{2}, \sigma_{3}\right)$. Directions $\vec{e}_{2}$ and $\vec{e}_{\mathrm{r}}$ always coincide and PSAR occurs in $\left(\vec{e}_{\theta}, \vec{e}_{\mathrm{z}}\right)$ directions. To simplify the rotation tensor writing, $\left(\vec{e}_{\mathrm{I}}, \vec{e}_{\mathrm{II}}, \vec{e}_{\mathrm{III}}\right)$ base (corresponding to principal stresses $\left(\sigma_{\mathrm{I}}, \sigma_{\mathrm{II}}, \sigma_{\mathrm{III}}\right)$ defined in Eq. (3) is introduced. Then, PSAR occurs around $\vec{e}_{\mathrm{I}}$. The angle of $\operatorname{PSAR} \alpha_{\sigma}$ is defined as the angle between the major principal direction $\vec{e}_{\mathrm{III}}\left(=\vec{e}_{1}\right)$ and the vertical $\vec{e}_{\mathrm{z}}$ :

$$
2 \alpha_{\sigma}=\arctan \left(\frac{2 \tau}{\sigma_{\mathrm{a}}}\right)
$$

\section{TEST PROCEDURES}

\section{Tested Material}

The tested material is an air dried poor graded sand, called Hostun sand from its original location in France. This sand is quartz dominated and sub angular in shape with grading curve characteristics as summarized in Table 1. Deposit is made by air pluviation. The vibration method is used to obtain the desired initial void ratio. Moulds are removed while applying a partial vacuum of $20 \mathrm{kPa}$ (corresponding to an effective pressure of $20 \mathrm{kPa}$ ) within the sample. Then samples are isotropically consolidated to the desired confining pressure.
Table 1. Grading characteristics of Hostun sand used in the present study

\begin{tabular}{cccccccc}
\hline Passing & \multicolumn{3}{c}{ Diameter $(\mathrm{mm})$} & \multicolumn{2}{c}{ Coefficients } & \multicolumn{2}{c}{ Void ratios } \\
\hline \multirow{3}{*}{ Hostun } & $D_{10}^{*}$ & $D_{30}^{*}$ & $D_{60}^{*}$ & $C_{\mathrm{u}}^{* *}$ & $C_{\mathrm{c}}^{* *}$ & $e_{\min }^{* * *}$ & $e_{\max }^{* * *}$ \\
& 0.26 & 0.32 & 0.37 & 1.42 & 1.06 & 0.648 & 1.041 \\
\hline
\end{tabular}

* $D_{\mathrm{x}}$ defined by $\mathrm{x} \%$ passing particle size

** Coefficient of uniformity: $C_{\mathrm{u}}=D_{60} / D_{10}$ and coefficient of curvature: $C_{\mathrm{c}}=\left(D_{30}\right)^{2} /\left(D_{10} D_{60}\right)$

*** Hostun: after Flavigny et al. (1990)
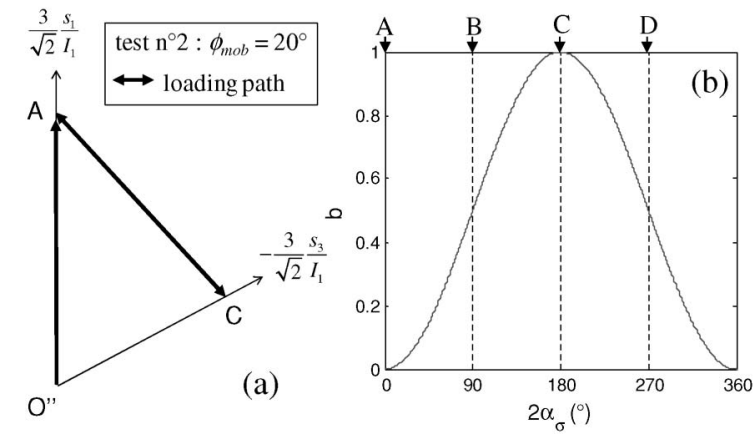

Fig. 4. Representation of the loading path which remains on the same Mohr-Coulomb surface in deviatoric normalized $\pi$ plane: $I_{1}=\operatorname{tr}(\sigma)$ $=\sqrt{3}$ (a)-Evolution of intermediate principal stress parameter $b$ as a function of $2 \alpha_{\sigma}$ (b)

\section{Stress Path}

The aim of the experimental campaign is to study the effects of PSAR on the elastic and plastic behaviours of dry sand. During the test, the angle of PSAR $\alpha_{\sigma}$ increases continuously at a constant rate while the principal stresses $\sigma_{1}$ and $\sigma_{3}$ remain always constant. Due to the HCA "T4C StaDy" design, intermediate principal stress $\sigma_{2}$ (which corresponds to confining pressure $P_{\mathrm{c}}$ ) varies between the two other principal stresses (Figs. 3, 4). Then the intermediate principal stress parameter $b=\left(\sigma_{2}-\sigma_{3}\right)$ / $\left(\sigma_{1}-\sigma_{3}\right)$ and also the Lode angle change during the test. The following relationship shows the link between $\alpha_{\sigma}$ and $b$ (Fig. 4(b)):

$$
b=\frac{1-\cos \left(2 \alpha_{\sigma}\right)}{2}
$$

In order to apply this particular stress path, the radius and center of the Mohr-Coulomb circle, respectively: $\tau_{\max }$ $=\sqrt{\left(\sigma_{\mathrm{a}} / 2\right)^{2}+\tau^{2}}$ and $P_{\mathrm{c}}+\sigma_{\mathrm{a}} / 2$ (Fig. 3), are kept unchanged during the test. These conditions are obtained experimentally by monitoring the three applied stresses $\left(P_{\mathrm{c}}, \sigma_{\mathrm{a}}, \tau\right)$ with cyclic sinusoidal evolutions at different phase lags. In this way, the mobilized Mohr-Coulomb angle $\phi_{\text {mob }}$ remains constant during PSAR (Fig. 4(a)):

$$
\sin \left(\phi_{\mathrm{mob}}\right)=\frac{\sigma_{1}-\sigma_{3}}{\sigma_{1}+\sigma_{3}}=\frac{\tau_{\mathrm{max}}}{P_{\mathrm{c}}+\frac{\sigma_{\mathrm{a}}}{2}}
$$

After removing the moulds and instrumenting the sample, isotropic consolidation is applied until an effective pressure of $80 \mathrm{kPa}$ (path from point $O$ to point $O^{\prime}$ in 

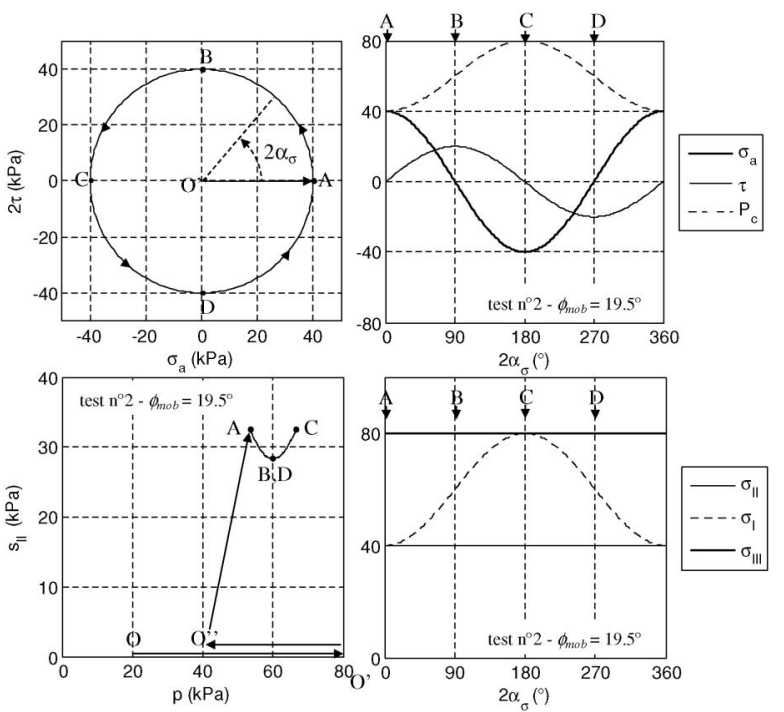

Fig. 5. Stress path of test $n^{\circ} 2$ in different axes: $\left(\sigma_{\mathrm{a}} ; 2 \tau\right)$ and $\left(p ; s_{\mathrm{II}}\right)$ -Representation of current stresses $\left(P_{\mathrm{c}}, \sigma_{\mathrm{a}}, \tau\right)$ and principal stresses $\left(\sigma_{\mathrm{I}}, \sigma_{\mathrm{II}}, \sigma_{\mathrm{III}}\right)$ as a function of $2 \alpha_{\sigma}$ during PSAR

Table 2. Characteristics of the PSAR tests conducted in this study

\begin{tabular}{cccccc}
\hline $\begin{array}{c}\text { test } \\
\mathrm{n}^{\circ}\end{array}$ & $\begin{array}{c}\tau_{\max } \\
(\mathrm{kPa})\end{array}$ & $\begin{array}{c}P_{\mathrm{c}}+\sigma_{\mathrm{a}} / 2 \\
(\mathrm{kPa})\end{array}$ & $\begin{array}{c}\phi_{\text {mob }} \\
\left({ }^{\circ}\right)\end{array}$ & $e_{0}$ & $\begin{array}{c}\text { number of } \\
\text { cycles }\end{array}$ \\
\hline 1 & 20 & 60 & 19.5 & 0.65 & 20 \\
2 & 20 & 60 & 19.5 & 0.84 & 20 \\
\hline 3 & 25 & 55 & 27.0 & 0.67 & 18 \\
4 & 25 & 55 & 27.0 & 0.83 & 15 \\
\hline
\end{tabular}

Figs. 4, 5) is achieved. The purpose of this consolidation is to remove irreversible deformations due to an isotropic plastic mechanism. Then the confining pressure is decreased to an isotropic state (point $O^{\prime \prime}$ in Figs. 4, 5) whose value depends on the test itself. A deviatoric path starts with a classical compression triaxial loading until point $A$. At this state, loading with PSAR begins. Four tests are preformed at two Mohr-Coulomb angles $\phi_{\text {mob }}$ and two initial void ratios $e_{0}$ (Table 2). For each test, a continuous rotation at a constant angular rate $\dot{\alpha}_{\sigma}=$ $0.018^{\circ} / \mathrm{s}$ is applied. This stress path is presented in Fig. 5 in different axes: $\left(\sigma_{\mathrm{a}} ; 2 \tau\right)$ and $\left(p ; s_{\mathrm{II}}\right)$ (where $p$ is the mean pressure, and $s_{\text {II }}$ the square of the second stress invariant $\left.s_{\mathrm{II}}=\sqrt{J_{2}}=\sqrt{S_{\mathrm{ij}} S_{\mathrm{ij}}}\right)$. Evolutions of the current stresses $\left(P_{\mathrm{c}}, \sigma_{\mathrm{a}}\right.$, $\tau)$ and principal stresses $\left(\sigma_{\mathrm{I}}, \sigma_{\mathrm{II}}, \sigma_{\mathrm{III}}\right)$ are also plotted as a function of $\alpha_{\sigma}$.

For each test, between 15 and 20 cycles are performed. Figure 6 represents the strain paths of the four considered tests plotted in $\left(\varepsilon_{z}-\varepsilon_{\theta} ; \gamma\right)$ axes. The origins of the strains are taken at the beginning of PSAR (i.e., for $\alpha_{\sigma}=$ $0^{\circ}$ or at point $\left.A\right)$. By comparing tests $\mathrm{n}^{\circ} 1$ and $2\left(\phi_{\mathrm{mob}}=\right.$ $\left.19.5^{\circ}\right)$ with tests $n^{\circ} 3$ and $4\left(\phi_{\operatorname{mob}}=27.0^{\circ}\right)$, the influence of $\phi_{\mathrm{mob}}$ is considered. Strain amplitudes increase with $\phi_{\text {mob }}$. On the other hand, by comparing tests $\mathrm{n}^{\circ} 1$ and 3 (medium density samples) with tests $\mathrm{n}^{\circ} 2$ and 4 (dense samples), more deformations are observed for medium density samples (as expected). However, the general strain shape
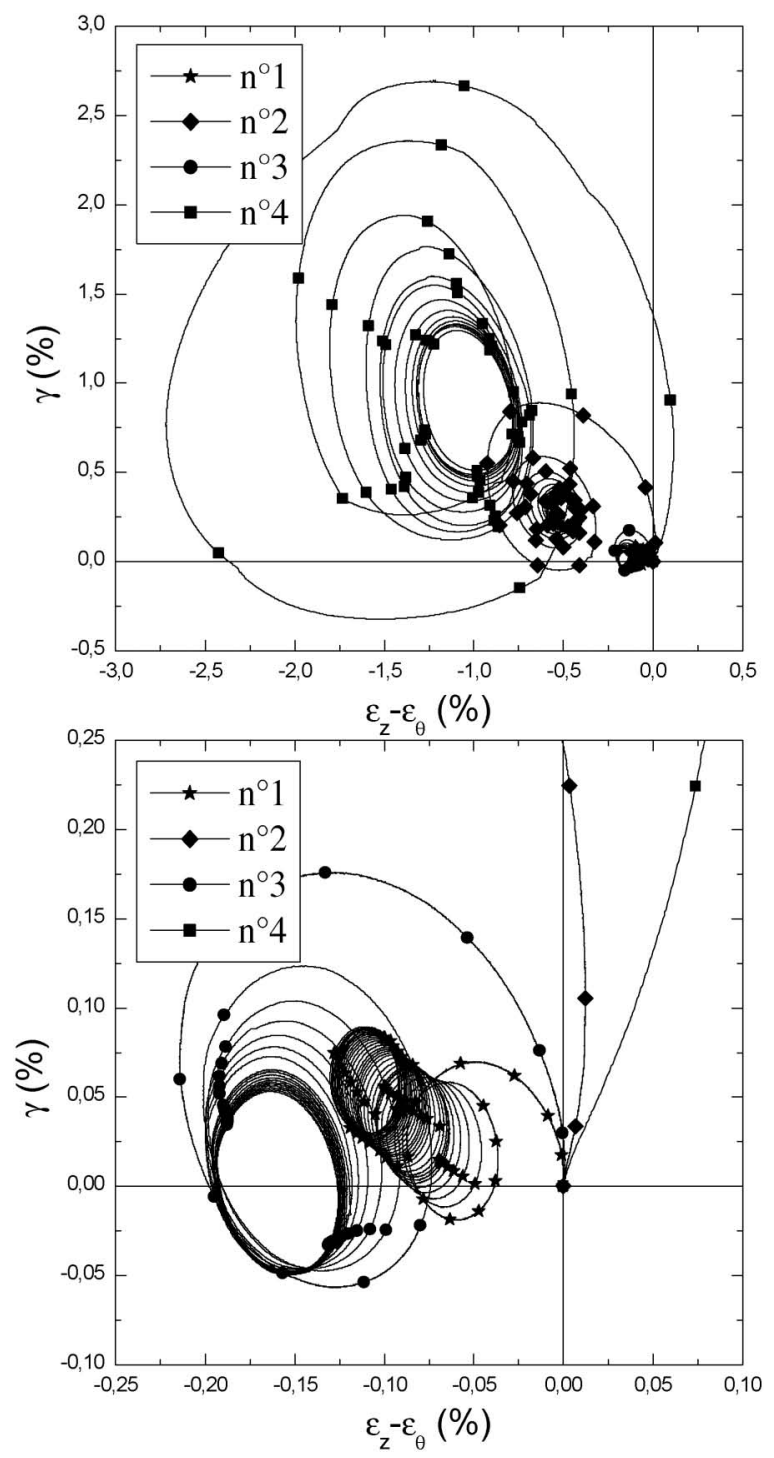

Fig. 6. Representation of the 4 tests in $\left(\varepsilon_{\mathrm{z}}-\varepsilon_{\theta} ; \gamma\right)$ axes (origins of strains are taken at the beginning of the PSAR, point $A$ )

is the same for all tests.

\section{Elastic Investigation}

In order to evaluate elastic deformation, an elastic investigation is conducted at the end of the test. Sixteen investigation points are selected on the circular stress path (Fig. 5). Once the investigation point is reached, a creep period of approximately two hours is observed in order to consume most of the viscous deformations that would otherwise occur during the elastic investigation period. Then two types of small quasi-static cyclic loadings are applied, i) a "pure axial loading" where only $\sigma_{z z}$ changes and ii) a "pure torsional loading" where only $\tau$ changes. The strain amplitudes of these cycles are small enough (about $10^{-5}$ ) to insure a negligible plastic part (Duttine, 2005; Di Benedetto et al., 2001). This elastic investigation procedure is explained in more detail in Duttine et al. (2007). 


\section{ELASTIC STRAIN DETERMINATION}

It is supposed that the strain increment is divided into two parts: an elastic strain increment $d \varepsilon_{\mathrm{ij}}^{\mathrm{e}}$ and a plastic strain increment $d \varepsilon_{\mathrm{ij}}^{\mathrm{p}}$ :

$$
d \varepsilon_{\mathrm{ij}}=d \varepsilon_{\mathrm{ij}}^{\mathrm{e}}+d \varepsilon_{\mathrm{ij}}^{\mathrm{p}}
$$

In order to obtain the correct plastic deformation values, the elastic part must be evaluated accurately and removed from the total deformation. A hypo-elastic model developed at ENTPE and named the DBGS (Di Benedetto et al., 2001) is presented and compared with experimental elastic investigations.

\section{Hypoelastic DBGS Model}

This rheological model is given by a hypo-elastic formulation. The general incremental form, for HCA geometry, of the hypo-elastic DBGS model (Di Benedetto et al., 2001) is given from Eq. (8) to Eq. (12):

$$
\begin{aligned}
& d \varepsilon_{\mathrm{ij}}^{\mathrm{e}}=M_{\mathrm{ijkl}}^{\mathrm{e}} d \sigma_{\mathrm{kl}} \\
& \left(\begin{array}{c}
d \varepsilon_{\mathrm{r}}^{\mathrm{e}} \\
d \varepsilon_{\theta}^{\mathrm{e}} \\
d \varepsilon_{\mathrm{z}}^{\mathrm{e}} \\
d \gamma^{\mathrm{e}} / \sqrt{2}
\end{array}\right)=\left(\begin{array}{llll}
M_{\mathrm{rr}}^{\mathrm{e}} & M_{\mathrm{r} \theta}^{\mathrm{e}} & M_{\mathrm{rz}}^{\mathrm{e}} & M_{\mathrm{r} \gamma}^{\mathrm{e}} \\
M_{\theta \mathrm{r}}^{\mathrm{e}} & M_{\theta \theta}^{\mathrm{e}} & M_{\theta z}^{\mathrm{e}} & M_{\theta \gamma}^{\mathrm{e}} \\
M_{\mathrm{zr}}^{\mathrm{e}} & M_{\mathrm{zr}}^{\mathrm{e}} & M_{\mathrm{zz}}^{\mathrm{e}} & M_{\mathrm{z \gamma}}^{\mathrm{e}} \\
M_{\gamma \mathrm{r}}^{\mathrm{e}} & M_{\gamma \theta}^{\mathrm{e}} & M_{\gamma \mathrm{z}}^{\mathrm{e}} & M_{\gamma \gamma}^{\mathrm{e}}
\end{array}\right)\left(\begin{array}{c}
d \sigma_{\mathrm{rr}} \\
d \sigma_{\theta \theta} \\
d \sigma_{\mathrm{zz}} \\
\sqrt{2} d \tau
\end{array}\right)
\end{aligned}
$$

where $d \varepsilon^{\mathrm{e}}$ and $d \sigma$ are the elastic strain and stress increments. $M^{\mathrm{e}}$ is the rheological compliance tensor which is independent of stress increment direction. Moreover, experimental results exhibit a symmetrical tensor $M^{\mathrm{e}}\left(M_{\mathrm{ij}}^{\mathrm{e}}=\right.$ $\left.M_{\mathrm{ji}}^{\mathrm{e}}\right)$ (Duttine et al., 2007). The DBGS model gives the following anisotropic (orthotropic) and symmetrical expression of the tensor $M^{\mathrm{e}}$ :

$$
M^{\mathrm{e}}=\frac{1}{f(e)} \frac{\bar{S}_{\mathrm{v}} \cdot \bar{\Sigma}_{\mathrm{p}}+{ }^{\mathrm{t}} \bar{S}_{\mathrm{v}} \cdot{ }^{\mathrm{t}} \bar{\Sigma}_{\mathrm{p}}}{2}
$$

with $f(e)$ a function of the void ratio: $f(e)=C_{\mathrm{g}}(b-e)^{2} /(1$ $+e$ ) where $\left\{C_{\mathrm{g}} ; b\right\}$ are two of the material's constants. The transpose function is denoted by 't"', and $\left\{S_{\mathrm{v}} ; \Sigma_{\mathrm{p}}\right\}$ are the tensors originally defined by Hardin and Blandford (1989) which take the following forms for HCA geometry when expressed in the principal stress axes $\left(\vec{e}_{\mathrm{I}}, \vec{e}_{\mathrm{II}}\right.$, $\left.\vec{e}_{\text {III }}\right)$ :

$$
\begin{aligned}
& \bar{S}_{\mathrm{v}}=\left(\begin{array}{cccc}
1 & -v_{0} & -v_{0} & 0 \\
-v_{0} & 1 & -v_{0} & 0 \\
-v_{0} & -v_{0} & 1 & 0 \\
0 & 0 & 0 & 1+v_{0}
\end{array}\right) \\
& \bar{\Sigma}_{\mathrm{p}}=\left(\begin{array}{cccc}
\frac{1}{\sigma_{\mathrm{I}}^{\mathrm{m}}} & 0 & 0 & 0 \\
0 & \frac{1}{\sigma_{\mathrm{II}}^{\mathrm{m}}} & 0 & 0 \\
0 & 0 & \frac{1}{\sigma_{\mathrm{III}}^{\mathrm{m}}} & 0 \\
0 & 0 & 0 & \frac{1}{\sigma_{\mathrm{II}}^{\mathrm{m} / 2} \sigma_{\mathrm{III}}^{\mathrm{m} / 2}}
\end{array}\right)
\end{aligned}
$$

where $\left\{m ; v_{0}\right\}$ are two constants which stand respectively for power coefficient and Poisson's ratio value for an
Table 3. Constants of DBGS model (Duttine, 2005)

\begin{tabular}{cccc}
\hline$C_{\mathrm{g}}$ & $b$ & $v_{0}$ & $m$ \\
\hline 1003 & 1.68 & 0.175 & 0.44 \\
\hline
\end{tabular}
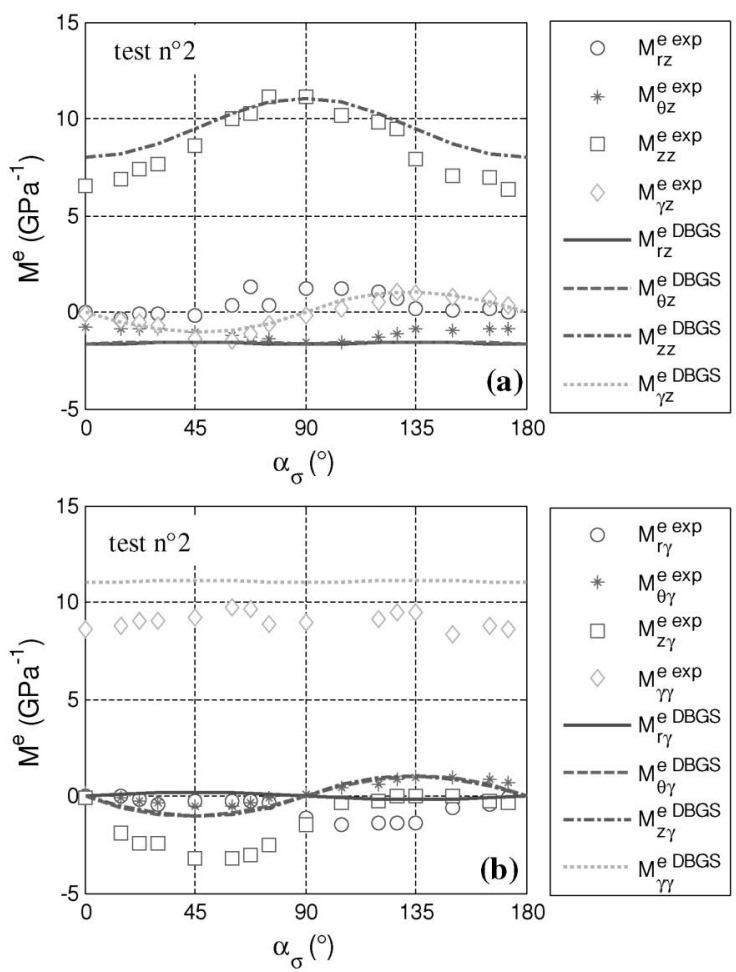

Fig. 7. $M_{\mathrm{ij}}^{\mathrm{e}}$ values obtained for test $\mathrm{n}^{\circ} \mathbf{2}$ from quasi-static small amplitude cyclic loadings in different directions (pure axial (a) and pure torsion (b)) performed at different stress levels i) data points and ii) simulation with DBGS hypo-elastic model (lines and dashed lines)

isotropic stress state.

Previous experimental campaigns conducted on dry Hostun sand at different void ratios and confining pressures (Duttine, 2005) allowed for four of the constants of the model for this sand to be evaluated (Table 3 ).

The APPENDIX includes a method which can be used to manipulate this tensor with PSAR when the $\left(\vec{e}_{\mathrm{r}}, \vec{e}_{\theta}, \vec{e}_{\mathrm{z}}\right)$ base and the principal base $\left(\vec{e}_{\mathrm{I}}, \vec{e}_{\mathrm{II}}, \vec{e}_{\mathrm{III}}\right)$ do not coincide.

\section{Experiments Analysis and Simulation}

As exposed previously, two types of small quasi static cyclic loadings are applied. One is purely in the axial direction (only $d \sigma_{z z}$ is not nil) giving four terms of the elastic tensor $\left(M_{\mathrm{rz}}^{\mathrm{e}}, M_{\theta \mathrm{z}}^{\mathrm{e}}, M_{\mathrm{zz}}^{\mathrm{e}}, M_{\gamma \mathrm{z}}^{\mathrm{e}}\right)$, while the other one is purely in torsion (only $d \tau$ is not nil) in order to directly obtain four other terms $\left(M_{\mathrm{r} \gamma}^{\mathrm{e}}, M_{\theta \gamma}^{\mathrm{e}}, M_{z \gamma}^{\mathrm{e}}, M_{\gamma \gamma}^{\mathrm{e}}\right)$ (Eq. (9)). To remain within the elastic domain, the amplitude of quasi-static loading is $1 \mathrm{kPa}$ (resp. $0.5 \mathrm{kPa}$ ) for axial (resp. torsional) loading. Strain amplitudes remain also below some $10^{-6}$, considered as the elastic limit. Experimental results for test $\mathrm{n}^{\circ} 2$ are presented. In Fig. 7, the evolution with $\alpha_{\sigma}$ of the 8 terms of the elastic tensor obtained from experimental data is plotted for test $n^{\circ} 2$. Some terms show important changes during PSAR. For 


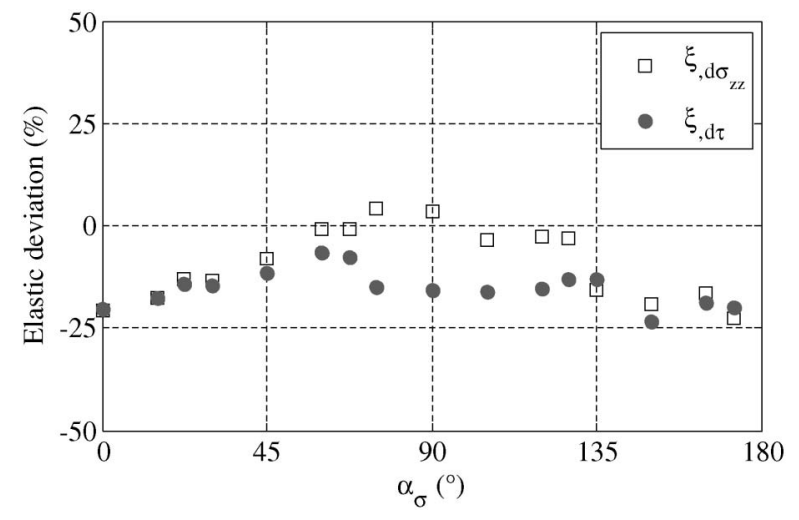

Fig. 8. Elastic strain deviation $\xi$ between DBGS model and experimental values obtained for an axial stress increment (only $d \sigma_{\mathrm{zz}}$ $\neq 0$ ) and for a shear stress increment (only $d \tau \neq 0$ ) at the 16 elastic investigation points

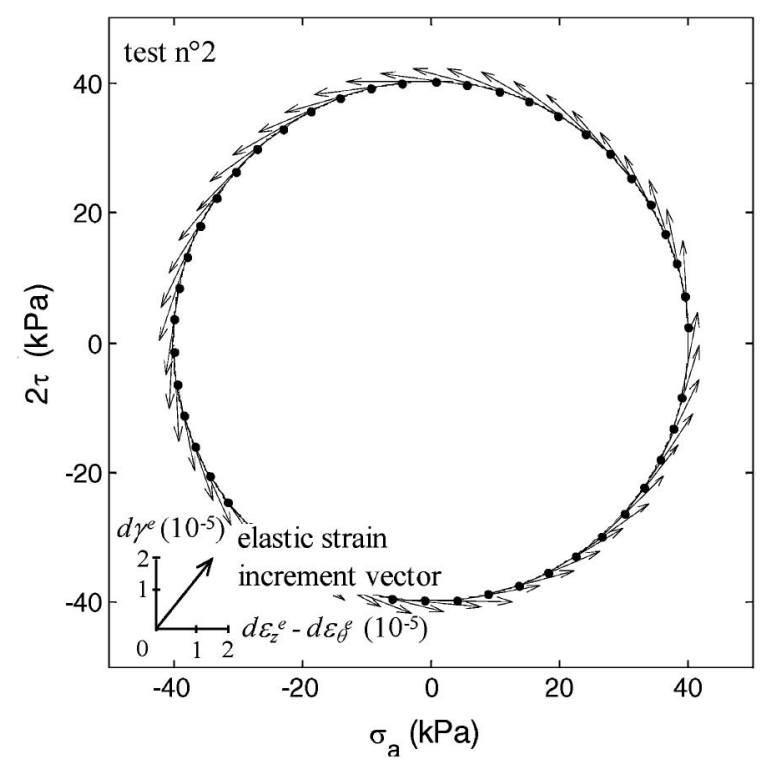

Fig. 9. Simulated elastic strain increment vectors $d \varepsilon^{\mathrm{e}}$ (obtained for $d \alpha_{\sigma}$ $\left.=1.8^{\circ}\right)$ in $\left(d \varepsilon_{\mathrm{z}}^{\mathrm{e}}-d \varepsilon_{\theta}^{\mathrm{e}} ; d \gamma^{\mathrm{e}}\right)$ axes for different stress levels in $\left(\sigma_{\mathrm{a}} ; 2 \tau\right)$ axes (test $\left.n^{\circ} 2\right)$

example, $M_{\mathrm{zz}}^{\mathrm{e}}$, which is independent of $\sigma_{\mathrm{II}}$ (the only principal stress which changes during the test), is nearly doubled between $\alpha_{\sigma}=0^{\circ}$ and $\alpha_{\sigma}=90^{\circ}$. On Fig. 7, simulations made with the DBGS model are also plotted for test $\mathrm{n}^{\circ} 2$ using constants of Table 3 .

In order to evaluate the accuracy of DBGS model predictions, simulated $\left(\left\|d \varepsilon^{\mathrm{e}}\right\|_{, \mathrm{d} \sigma_{z z}}^{\mathrm{DBSS}}\right)$ and experimental $\left(\left\|d \varepsilon^{\mathrm{e}}\right\|_{, \mathrm{d} \sigma_{n}}^{\exp }\right)$ norms of the elastic deformation obtained for an axial stress increment (only $d \sigma_{z z}$ is not nil) (Eq. (13)) are compared. The deviation $\xi_{\text {,d } \sigma_{n z}}$ (Eq. (14)) between DBGS model and experimental values is plotted in Fig. 8 for the 16 elastic investigation points. The same analysis is conducted for the norm of the elastic deformation tensor due to a shear stress increment (only $d \tau$ is not nil) (Fig. 8). The deviations are always smaller than $25 \%$. Considering the experimental scatter due to device accuracy, the DBGS model simulations can be considered reasonably acceptable even for important PSAR.

$$
\begin{aligned}
& \left\{\begin{array}{l}
\left\|d \varepsilon^{\mathrm{e}}\right\|_{, \mathrm{d} \sigma_{z z}}=\sqrt{M_{\mathrm{rz}}^{\mathrm{e} 2}+M_{\theta z}^{\mathrm{e} 2}+M_{\mathrm{zz}}^{\mathrm{e} 2}+M_{\gamma z}^{\mathrm{e} 2}} d \sigma_{\mathrm{zz}} \\
\left\|d \varepsilon^{\mathrm{e}}\right\|_{, \mathrm{d} \tau}=\sqrt{M_{\mathrm{r} \gamma}^{\mathrm{e} 2}+M_{\theta \gamma}^{\mathrm{e} 2}+M_{z \gamma}^{\mathrm{e} 2}+M_{\gamma \gamma}^{\mathrm{e} 2}} \sqrt{2} d \tau
\end{array}\right. \\
& \xi_{, \mathrm{d} \sigma_{z z}}=\frac{\left\|d \varepsilon^{\mathrm{e}}\right\|_{, \mathrm{d} \sigma_{z z}}^{\exp }-1 ; \quad \xi_{, \mathrm{d} \tau}=\frac{\left\|d \varepsilon^{\mathrm{e}}\right\|_{, \mathrm{d} \tau}^{\exp }}{\left\|d \varepsilon^{\mathrm{e}}\right\|_{, \mathrm{d} \sigma_{z z}}^{\mathrm{DBGS}}}-1}{\left\|d \varepsilon^{\mathrm{e}}\right\|_{, \mathrm{d} \tau}^{\mathrm{DBGS}}}
\end{aligned}
$$

For test $\mathrm{n}^{\circ} 2$, the simulated elastic strain increment vector $d \varepsilon^{\mathrm{e}}$ obtained for a stress increment vector $d \sigma$ (which is the difference between the stress tensor at $\alpha_{\sigma}$ and $\alpha_{\sigma}+d \alpha_{\sigma}$ with $\left.d \alpha_{\sigma}=1.8^{\circ}\right)$ is plotted (Fig. 9) in the $\left(d \varepsilon_{z}^{\mathrm{e}}-d \varepsilon_{\theta}^{\mathrm{e}} ; d \gamma^{\mathrm{e}}\right)$ axes for different stress levels in the $\left(\sigma_{\mathrm{a}} ; 2 \tau\right)$ axes. The simulated elastic strain increment direction is very close to the tangent vector at the circle described in the $\left(\sigma_{a} ; 2 \tau\right)$ axes. As explained later, this tangential direction is a noncoaxial direction. Therefore, during the test, the quasi totality of elastic deformation is in the non-coaxial direction. For this reason, as underlined previously, accurately evaluating the elastic part is a key point in the study of plastic deformation, especially its non-coaxial part.

\section{PLASTIC MECHANISMS}

Plastic deformation is obtained after removing the elastic deformation (simulated by DBGS model) from the total deformation. Figure 10 represents the total (Fig. 10(a)), elastic (Fig 10(b)) and plastic (Fig. 10(c)) strain paths during 3 rd cycle of test $n^{\circ} 2$. Origins of strains are taken at the beginning of the considered cycle (i.e., for $\alpha_{\mathrm{s}}$ $=0^{\circ}$ ). During this cycle, few volume changes happen and there is nearly no volume variation between the beginning and the end of this cycle. Meanwhile, as it is usual for a medium loose sample $\left(e_{0}=0.84\right)$, the sample contracts slightly after one cycle. This volume variation is too small to have an impact on the value of function $f(e)$ (Eq. (10)). Considering this, the hypothesis of no volume change during cyclic loading was chosen. As a result, simulated elastic strains remain the same for all cycles. Figure 11 represents the elastic, plastic and total strains in the $\left(\varepsilon_{z}-\right.$ $\left.\varepsilon_{\theta} ; \gamma\right)$ axes for cycle 3 and cycle 20 of test $\mathrm{n}^{\circ} 2$. In this figure, the 3rd (Fig. 11(a)) and the 20th (Fig. 11(b)) cycles can be compared. The plastic strain amplitudes decrease significantly between the $3 \mathrm{rd}$ and 20 th cycles (almost by a factor of 3). Meanwhile, even after 20 cycles, plastic deformation remains greater than elastic deformation.

Two main plastic mechanisms (Eq. (15)) are considered:

$$
d \varepsilon_{\mathrm{ij}}^{\mathrm{p}}=d \varepsilon_{\mathrm{ij}}^{\mathrm{pc}}+d \varepsilon_{\mathrm{ij}}^{\mathrm{pnc}}
$$

The first terms corresponds to one (or more) coaxial plastic mechanism(s), noted by "pc", which maintains coaxiality between the principal directions of stress and the plastic strain increment. It is classically accepted that this mechanism takes the evolutions of mean pressure and deviatoric stress slightly. In order to minimize the effect of the mean pressure, an isotropic pre-consolidation (up to $80 \mathrm{kPa}$ ) is performed before each test. The deviatoric effects can be considered relatively small. Indeed, in the normalized deviatoric plan $\left(I_{1}=\operatorname{tr}(\sigma)=\sqrt{3}\right)$, the applied 

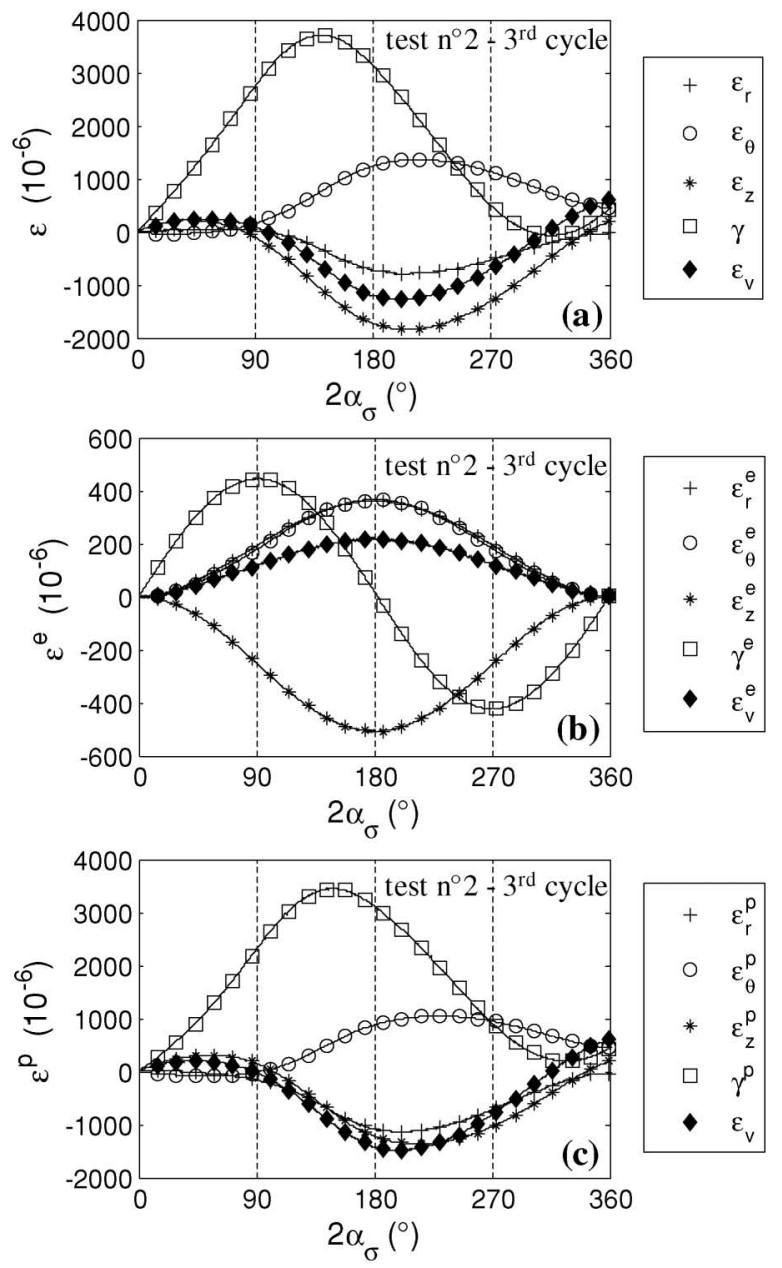

Fig. 10. Total (a), elastic (b) and plastic (c) strains during cycle 3 of test $\mathrm{n}^{\circ} 2$ as a function of $\alpha_{\sigma}$

stress path, remains on the same Mohr-Coulomb surface (Fig. 4(a)) ( $\phi_{\text {mob }}$ is constant, Eq. (6)). Nevertheless, Lode's angle $\theta$ or $b$ (Eq. (5)) value changes during the test, which may be the result of deformation due to a classical coaxial mechanism. However, this doesn't change the proposed analysis of non-coaxial plastic mechanism.

The second terms of Eq. (15) corresponds to a noncoaxial mechanism, noted by "pnc", which indeed plays a very important role during tests with PSAR. It is studied in the next section. It should be noted here that, when expressed in principle stress axes, a non-coaxial $X^{\text {"nc" ten- }}$ sor has nil terms on the diagonal. It is orthogonal to a coaxial $X^{\prime \prime c "}$ tensor as $X_{\mathrm{ij}}^{\text {"nc" }} \cdot X_{\mathrm{ij}}^{\text {"ce" }}=0$.

\section{NON-COAXIAL FLOW RULE}

As noted in introduction, more and more experimental evidence shows the existence of non-coaxial plastic behaviour. Unlike usual plastic theory where principal directions of stress and the principal directions of plastic strain increment are the same, there is a non-coaxial strain increment vector which responds to a non-diagonal loading stress increment tensor (when expressed in the principal directions of stress). The yield vertex theory
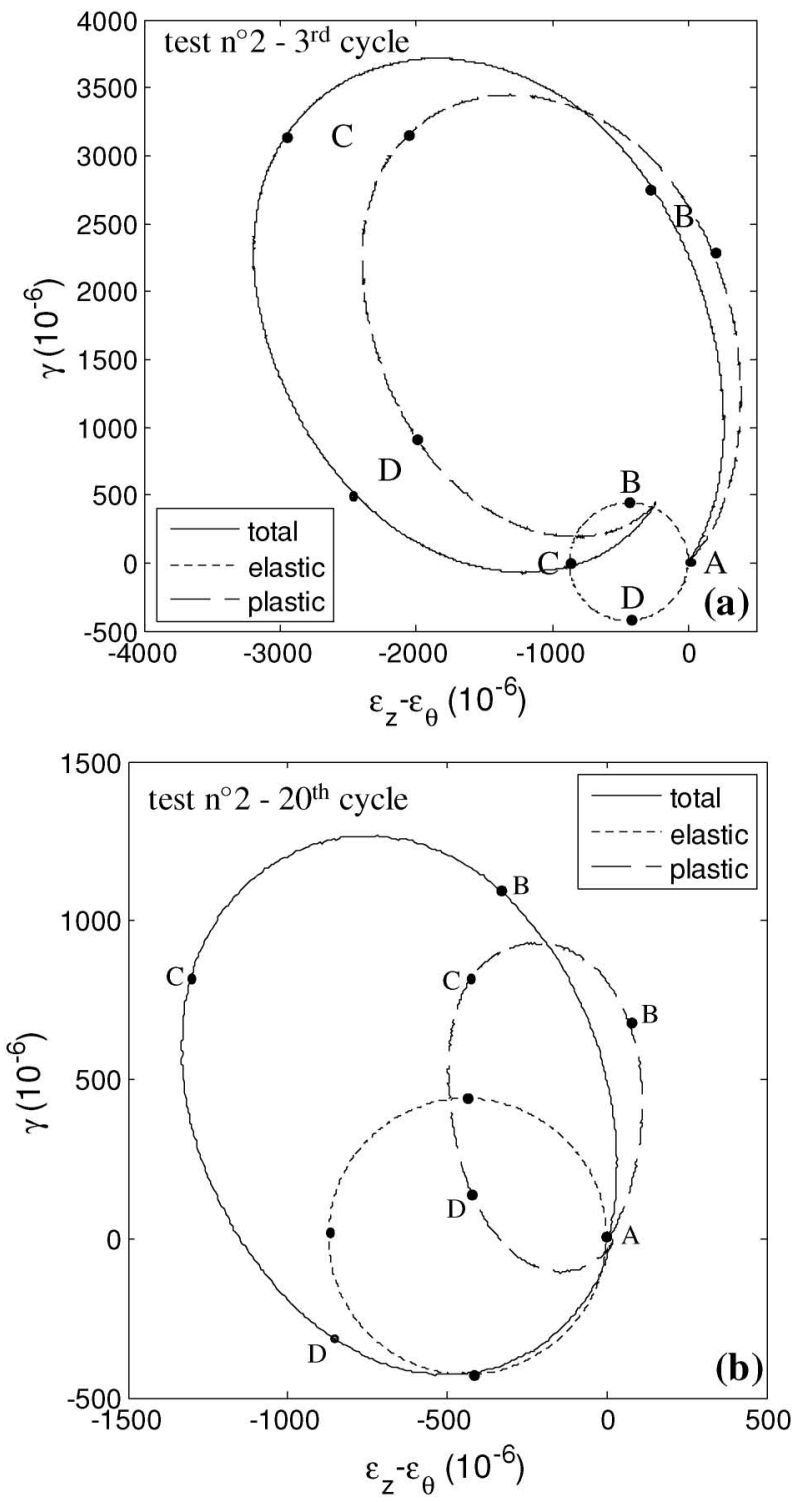

Fig. 11. Representation of total, elastic (simulated by DBGS model) and plastic strains in $\left(\varepsilon_{\mathrm{z}}-\varepsilon_{\theta} ; \gamma\right)$ axes (origins of strains are taken at the beginning of the cycle) for the 3 rd cycle (a) and the 20th cycle (b) of test $n^{\circ} 2$ (points $A B C D$ are defined in Fig. 4)

proposed by Rudnicki and Rkce (1975) has been largely accepted to simulate this non-coaxial effect. In this theory, a non-coaxial plastic deformation increment $d \varepsilon_{\mathrm{ij}}^{\mathrm{pnc}}$ is assumed to be proportional to the non-coaxial stress increment $d s_{\mathrm{ij}}^{\mathrm{nc}}$ :

$$
d \varepsilon_{\mathrm{ij}}^{\mathrm{pnc}}=d e_{\mathrm{ij}}^{\mathrm{pnc}}=\frac{1}{H^{\mathrm{pnc}}} d s_{\mathrm{ij}}^{\mathrm{nc}}
$$

where $H^{\text {pnc }}$ is the plastic modulus which governs the noncoaxial mechanism. It must be noted that this mechanism is purely deviatoric; no volume variation is introduced: $d \varepsilon_{\mathrm{ij}}^{\mathrm{pnc}}=d e_{\mathrm{ij}}^{\mathrm{pnc}}$. In the next section, the general decomposition in a coaxial and a non-coaxial part is presented.

\section{Non-coaxial Decomposition}

The general mathematical decomposition of any tensor $X$ in a coaxial part "c" and a non-coaxial part "nc" rela- 
tively to a stress basis is given by Eq. (17).

$$
\left\{\begin{array}{l}
X_{\mathrm{ij}} " \mathrm{c} "=\frac{X_{\mathrm{kl}} \delta_{\mathrm{kl}}}{3} \delta_{\mathrm{ij}}+\frac{X_{\mathrm{kl}} S_{\mathrm{k}}}{S_{\mathrm{kl}} S_{\mathrm{kl}}} S_{\mathrm{ij}}+\frac{X_{\mathrm{kl}} S_{\mathrm{kl}}}{S_{\mathrm{kl}} S_{\mathrm{kl}}} S_{\mathrm{ij}} \\
X_{\mathrm{ij}} \mathrm{nc}=X_{\mathrm{ij}}-X_{\mathrm{ij}} \mathrm{cc} "
\end{array}\right.
$$

where $\delta$ is Kroneker delta, $s$ is the deviatoric part of $\sigma$ and $S$ is a tensor orthogonal to $I$ (identity) and $S$ (Eq. (18)).

$$
\left\{\begin{array}{l}
\delta_{\mathrm{ij}}=\left\{\begin{array}{l}
1 \text { if } i=j \\
0 \text { if } i \neq j
\end{array}\right. \\
S_{\mathrm{ij}}=\sigma_{\mathrm{ij}}-\frac{1}{3} \operatorname{tr}(\sigma) \delta_{\mathrm{ij}} \\
S_{\mathrm{ij}}=S_{\mathrm{ik}} S_{\mathrm{kj}}-\frac{1}{3} J_{2} \delta_{\mathrm{ij}}-\frac{J_{3}}{J_{2}} S_{\mathrm{ij}}
\end{array}\right.
$$

$I, s$ and $S$ are orthogonal to $X$ "nc" (Eq. (19)).

$$
X_{\mathrm{ij}}^{\mathrm{nc}} \delta_{\mathrm{ij}}=0 ; X_{\mathrm{ij}}^{\mathrm{nc}} s_{\mathrm{ij}}=0 ; X_{\mathrm{ij}}^{\mathrm{nc}} S_{\mathrm{ij}}=0
$$

$X$ is either thestress increment $d \sigma$, the strain increment $d \varepsilon$, the elastic strain increment $d \varepsilon^{\mathrm{e}}$ or the plastic strain increment $d \varepsilon^{\mathrm{p}}$.

In the case of the performed tests, the decomposition of plastic strain increments (and the stress increment) can be represented in Fig. 12 at a current stress level $\left(\sigma_{\mathrm{a}} ; 2 \tau\right)$ when considering the axes $\left(d \varepsilon_{z}^{\mathrm{p}}-d \varepsilon_{\theta}^{\mathrm{p}} ; d \gamma^{\mathrm{p}}\right)$. The rotation angle of principal plastic strain increment directions $\alpha_{\mathrm{d} \varepsilon^{\mathrm{p}}}$ is defined between the vertical direction (represented by horizontal axis in Fig. 12) and plastic strain increment $d \varepsilon^{\mathrm{p}}$ direction. The normal at the circular loading path represents the coaxial direction, whereas the tangent represents the non-coaxial direction. The plastic strain increment vector is projected on these two directions to obtain its coaxial and non coaxial parts (Eq. (17)). Figure 12 shows also the stress increment $d \sigma$, which is totally noncoaxial in these axes. The following relationship is obtained between the rotation angles of the principal stress directions $\alpha_{\sigma}$ and the principal stress increment directions $\alpha_{\mathrm{d} \sigma}$ :

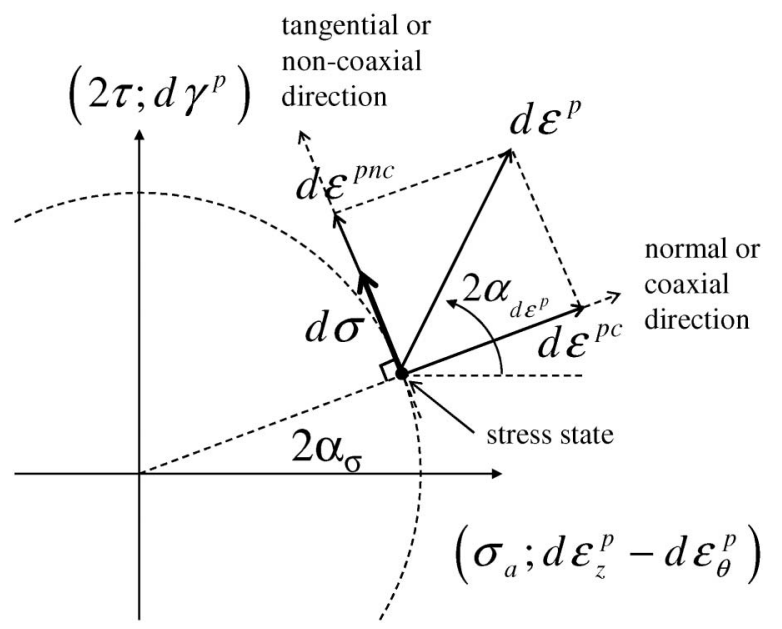

Fig. 12. Decomposition of plastic strain increment vector in a coaxial and a non-coaxial vector in $\left(\sigma_{\mathrm{a}} ; 2 \tau\right)$ axes (for stress) and $\left(d \varepsilon_{\mathrm{z}}^{\mathrm{p}}-d \varepsilon_{\theta}^{\mathrm{p}}\right.$; $d \gamma^{\mathrm{p}}$ ) axes (for strain)_Definition of principal plastic strain increment rotation $\alpha_{\mathrm{d} \varepsilon^{p}}$

$$
\alpha_{\mathrm{d} \sigma}=\alpha_{\sigma}+45^{\circ}
$$

The DBGS model formulation gives an elastic strain increment $d \varepsilon^{\mathrm{e}}$ that is mainly non-coaxial. As such, the elastic part of strain increment impacts directly on the amplitude of the non-coaxial strain increment. For this reason, a good evaluation and simulation of elastic deformation are very important. In this paper, great care has been taken on that point.

\section{Experimental Results Analysis}

In Blanc (2011), similar trends were presented for the three other tests. The focus was on the 3rd and 20 th cycles in order to study evolution with the number of cycles. The first two cycles were not considered since creep periods were applied at different levels. In order to compare the strain increments, the variation of stress rotation for each increment is always $d \alpha_{\sigma}=1.8^{\circ}$ (i.e., every $100 \mathrm{~s}$ because tests are performed at constant rotation rate $\dot{\alpha}_{\sigma}=$ $0.018^{\circ} / \mathrm{s}$ ).

The plastic strain increment vector of the 3rd cycle is plotted in Fig. 13. The amplitude and direction of this vector are not constant during the cycle. Using the decomposition presented in Fig. 12, it is easy to observe that plastic strain increment vector has not only a coaxial component but also a non-coaxial (tangential) part. It denotes the existence of non-coaxial plastic behaviour. In Fig. 14(a), rotation angles of the stress $\alpha_{\sigma}$, stress increment $\alpha_{\mathrm{d} \sigma}$ and plastic strain increment $\alpha_{\mathrm{d} \varepsilon^{\mathrm{p}}}$ are presented during this 3rd cycle. Fig. 14(b) shows the evolution of the plastic strain increment direction $\alpha_{\mathrm{d} \varepsilon^{\mathrm{p}}}$ compared to the coaxial direction $\alpha_{\sigma}$. It shows a cyclic shape evolution, which has maximum values (points $M_{1}$ and $M_{2}$ in Fig. 14(b)) of about $10^{\circ}$ after pure axial compression-extension (i.e., after points $A$ and $C$ or for $\alpha_{\sigma}=0^{\circ}$ and $90^{\circ}$ ).

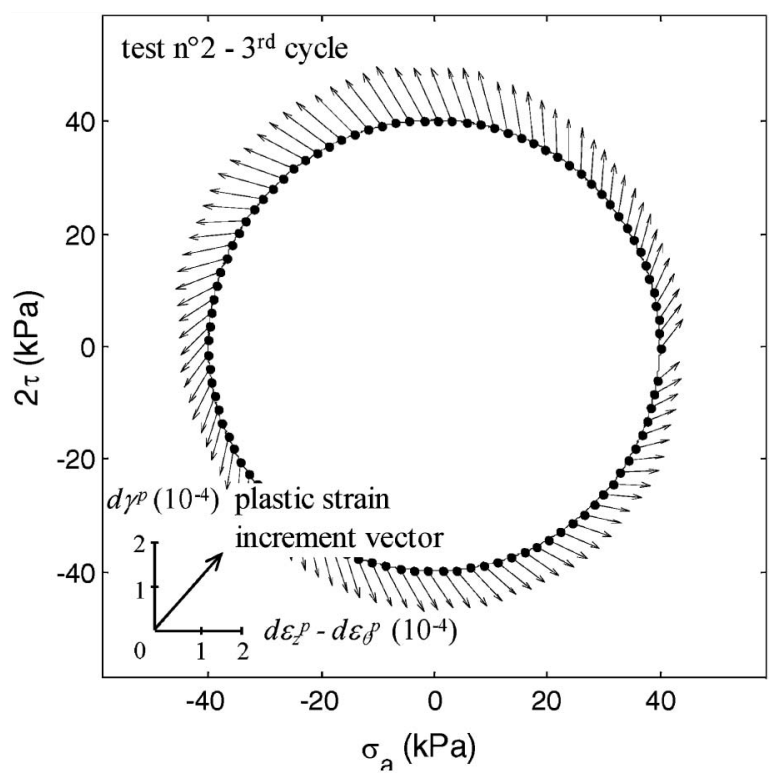

Fig. 13. Plastic strain increment vectors $d \varepsilon^{\mathrm{p}}$ (obtained for $d \alpha_{\sigma}=1.8^{\circ}$ ) in $\left(d \varepsilon_{\mathrm{z}}^{\mathrm{p}}-d \varepsilon_{\theta}^{\mathrm{p}} ; d \gamma^{\mathrm{p}}\right)$ axes for different stress levels in $\left(\sigma_{\mathrm{a}} ; 2 \tau\right)$ axes (test $\mathbf{n}^{\circ}$ ) 

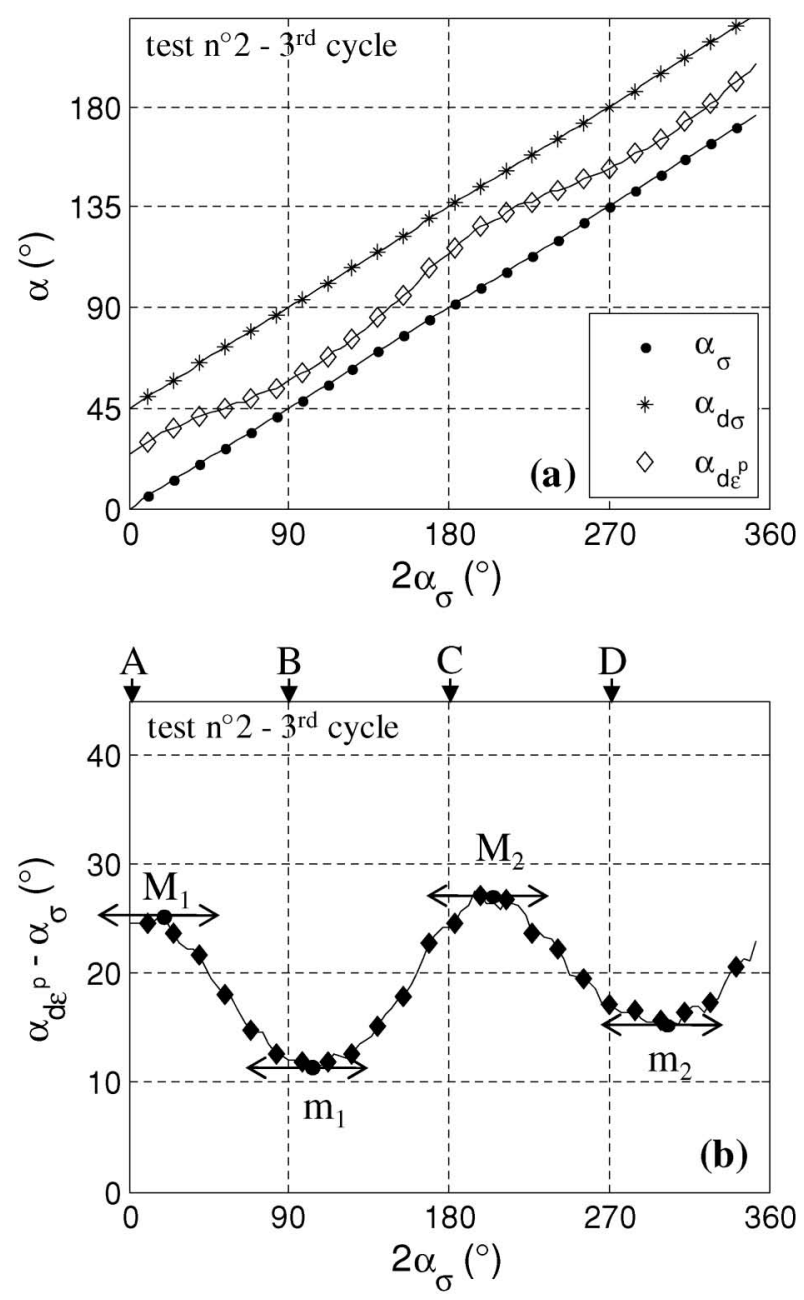

Fig. 14. Principal axes rotations of: stress $\alpha_{\sigma}$, stress increment $\alpha_{\mathrm{d} \sigma}$ and plastic strain increment $\alpha_{\mathrm{d} \varepsilon^{p}}$ (a) and evolution of directions of plastic strain increment $\alpha_{\mathrm{d} \varepsilon^{p}}-\alpha_{\sigma}$ (b), as a function of $\alpha_{\sigma}$ (test $\mathrm{n}^{\circ} 2-3$ rd cycle)

These maxima are obtained when the radial stress increment $d \sigma_{\text {rr }}$ is nearly nil. In contrast, $d \varepsilon^{\mathrm{p}}$ is close to the coaxial direction (points $m_{1}$ and $m_{2}$ in Fig. 13(b)) when $d \sigma_{\mathrm{rr}}$ is nearly maximum (points $B$ and $D$ ). At points $A$ and $C\left(\sigma_{\alpha}=0^{\circ}\right.$ and $\left.90^{\circ}\right)$ coaxial stress increment is nil $\left(d \sigma_{1}\right.$ $\left.=d \sigma_{2}=d \sigma_{3}=0\right)$. Figure 14 reveals that, in points $A$ and $C$, the plastic strain increment has a non-negligible coaxial part (a non coaxial part would give $\alpha_{\mathrm{d} \varepsilon^{\mathrm{p}}}-\alpha_{\sigma}=45^{\circ}$ ). It indicates coupling between the coaxial and non-coaxial plastic mechanisms. This coupling may be due to a difference between the principal strain (from isotropic states) directions $\alpha_{\varepsilon}$ and the principal stress directions $\alpha_{\sigma}$.

The components of the non-coaxial plastic stress increment tensor (Fig. 15(a)) and the non-coaxial plastic strain increment tensor (Figs. 15(b), (c)) are plotted as a function of $\alpha_{\sigma}$. Norms of these increment vectors, $d \tau_{\max }^{\mathrm{nc}}$ and $d \gamma_{\max }^{\text {pnc }}$, defined in Eqs. (21) and (22), are also plotted.

$$
\begin{aligned}
& d \tau_{\max }^{\mathrm{nc}}=\sqrt{\left(\frac{d s_{\mathrm{z}}^{\mathrm{nc}}-d s_{\theta}^{\mathrm{nc}}}{2}\right)^{2}+\left(d \tau^{\mathrm{nc}}\right)^{2}} \\
& d \gamma_{\max }^{\mathrm{pnc}}=\sqrt{2}\left\|d \varepsilon^{\mathrm{pnc}}\right\|=\sqrt{\left(d e_{\mathrm{z}}^{\mathrm{pnc}}-d e_{\theta}^{\mathrm{pnc}}\right)^{2}+\left(d \gamma^{\mathrm{pnc}}\right)^{2}}
\end{aligned}
$$
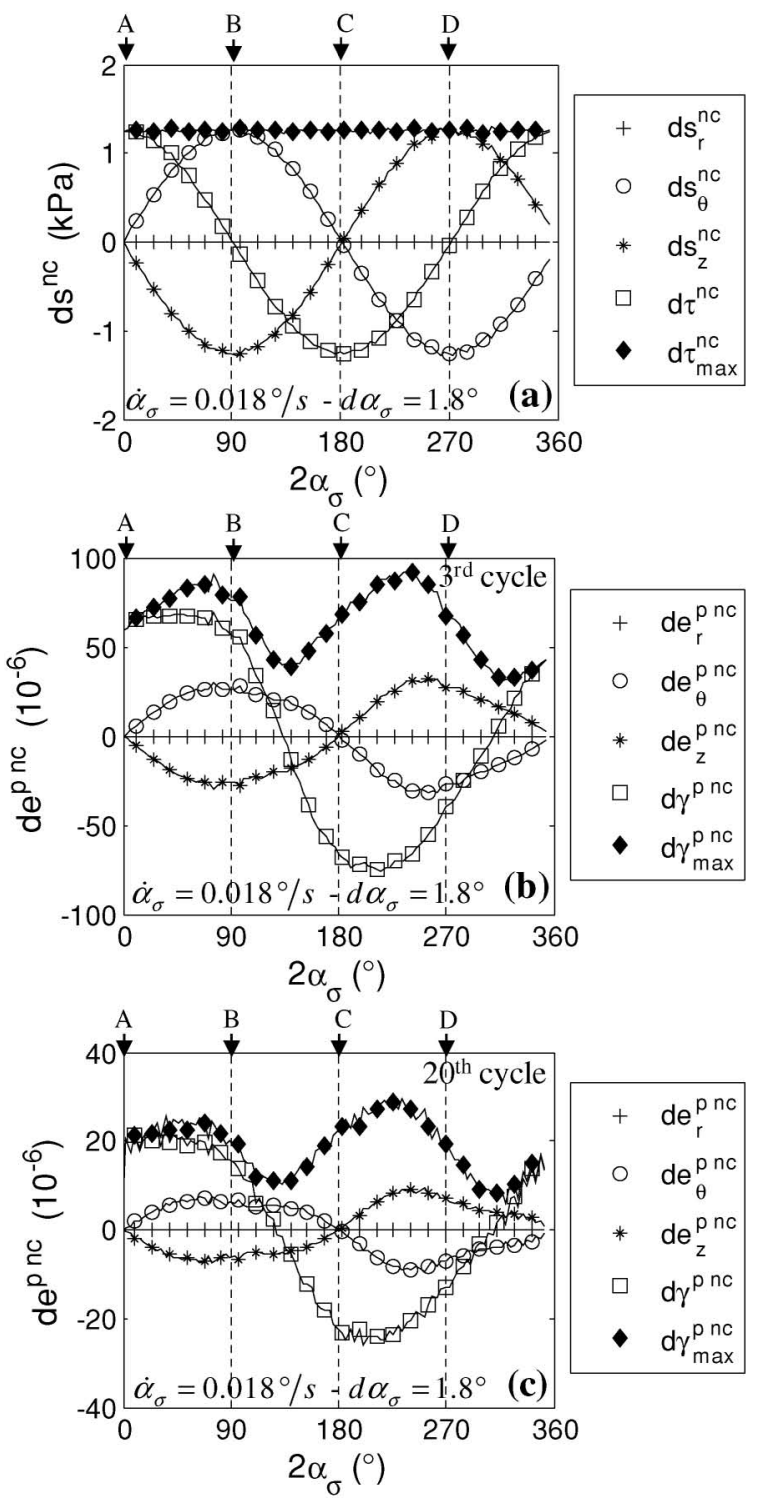

Fig. 15. Components of non-coaxial deviatoric stress increment tensor (a) and non-coaxial plastic strain increment tensor (3rd cycle (b) and 20th cycle (c)) as function of $\alpha_{\sigma}\left(\right.$ obtained for $\left.d \alpha_{\sigma}=1.8^{\circ}\right)$

$$
\sqrt{2}\left\|d \varepsilon^{\mathrm{p}}\right\|=\sqrt{2 d \varepsilon_{\mathrm{r}}^{\mathrm{p}^{2}}+2 d \varepsilon_{\theta}^{\mathrm{p}^{2}}+2 d \varepsilon_{\mathrm{z}}^{\mathrm{p}^{2}}+d \gamma^{\mathrm{p}^{2}}}
$$

Due to non-coaxial decomposition, the radial parts of these tensors are always nil $\left(d s_{\mathrm{r}}^{\mathrm{nc}}=0\right.$ and $\left.d e_{\mathrm{r}}^{\mathrm{pnc}}=0\right)$. In addition, $d s_{\mathrm{z}}^{\mathrm{nc}}$ (and $d e_{\mathrm{z}}^{\mathrm{pnc}}$ ) and $d s_{\theta}^{\mathrm{nc}}$ (and $d e_{\theta}^{\mathrm{pnc}}$ ) are always opposite. $d s_{\mathrm{z}}^{\mathrm{nc}}$ and $d s_{\theta}^{\mathrm{nc}}$ are nil at points $A$ and $C$. As the noncoaxial tensor has one dimension, only the amplitude $\left\|d \varepsilon^{\mathrm{pnc}}\right\|$ can be studied. While the amplitude of the noncoaxial stress increment $d \tau_{\max }^{\mathrm{nc}}$ is constant during the entire test, the non-coaxial plastic strain increment amplitude $\left\|d \varepsilon^{\text {pnc }}\right\|$, changes with $\alpha_{\sigma}$. The maximum amount of noncoaxial plastic deformation occurs at around $\alpha_{\sigma}=30^{\circ}$ and $120^{\circ}$ and the minimum is at around $\alpha_{\sigma}=70^{\circ}$ and $160^{\circ}$, indicating that the plastic non-coaxial modulus $H^{\mathrm{pnc}}$ is not constant during a cycle. It is, however, generally considered as a constant, as can be seen in Eq. (16).

The norm of the non-coaxial plastic strain increment $\left\|d \varepsilon^{\mathrm{pnc}}\right\|$ (resp. norm of non-coaxial plastic strain incre- 

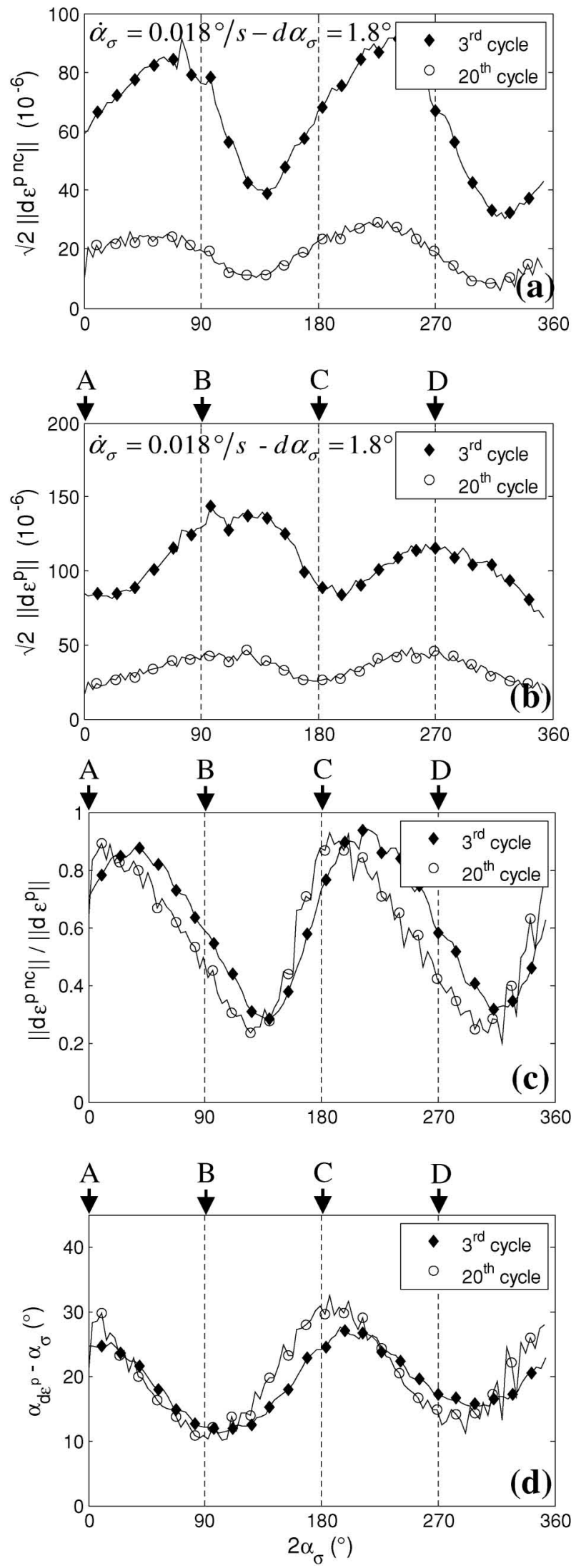

Fig. 16. Comparison of the norm of plastic non-coaxial strain increment $\left\|d \varepsilon^{\mathrm{pnc}}\right\|$ (a), norm of plastic strain increment $\left\|d \varepsilon^{\mathrm{p}}\right\|(\mathrm{b})$, their ratio (c) and direction of plastic strain increment $\alpha_{\mathrm{d} \varepsilon^{\mathrm{p}}-\alpha_{\sigma}}$ (d) for 3rd and 20 th cycles of test $n^{\circ} 2$ (obtained for $d \alpha_{\sigma}=1.8^{\circ}$ )
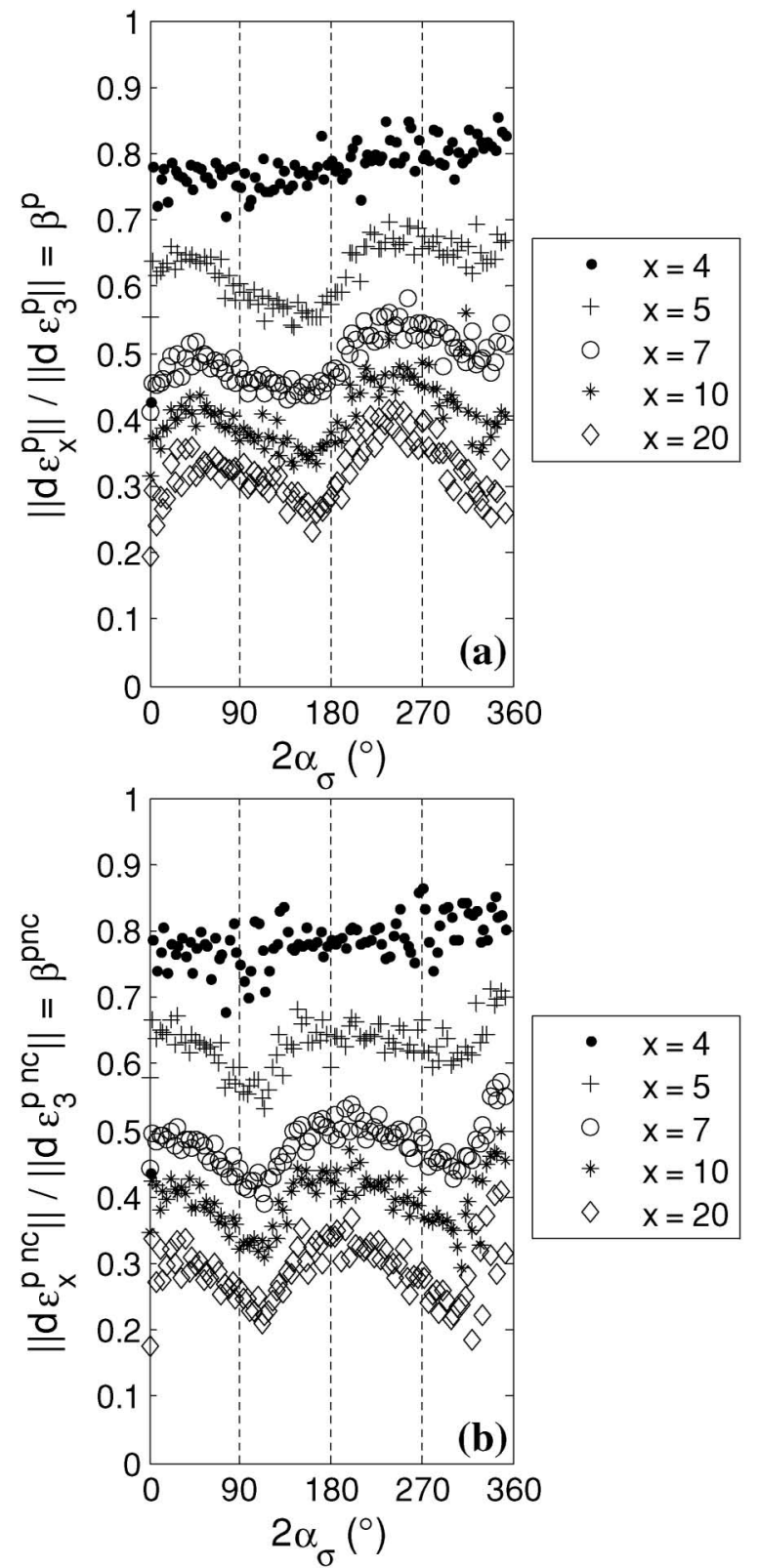

Fig. 17. Ratio between the norm of plastic strain increment $\left\|d \varepsilon^{\mathrm{p}}\right\|$ (a) and norm of plastic non-coaxial strain increment $\left\|d \varepsilon^{\mathrm{pnc}}\right\|$ (b) during cycle " $x$ " and the same values during the 3 rd cycle

ment $\left\|d \varepsilon^{\mathrm{p}}\right\|$ ) is plotted in Fig. 16(a) (resp. Fig. 16(b)) for the $3 \mathrm{rd}$ and the 20 th cycle. The ratio of these two norms, $\left\|d \varepsilon^{\mathrm{pnc}}\right\|$ and $\left\|d \varepsilon^{\mathrm{p}}\right\|$, is presented in Fig. 16(c). The noncoaxial part changes significantly during one cycle, from $20 \%$ to $90 \%$ of the total plastic amplitude. Even when the loading is purely non-coaxial (i.e., in points $A$ and $C$ ), there is some coaxial deformation (around 15\%). A noncoaxial stress increment induces coaxial deformations, suggesting a link between the coaxial and non-coaxial plastic mechanisms. A comparison between the 3rd and the 20th cycles allows the following interesting observations. The non-coaxial plastic strain increment keeps the same form between the 3rd and the 20th cycle but its amplitude is reduced by a factor of about 3 (Fig. 16(a)). This is proof of a non-coaxial cyclic hardening. The direction 


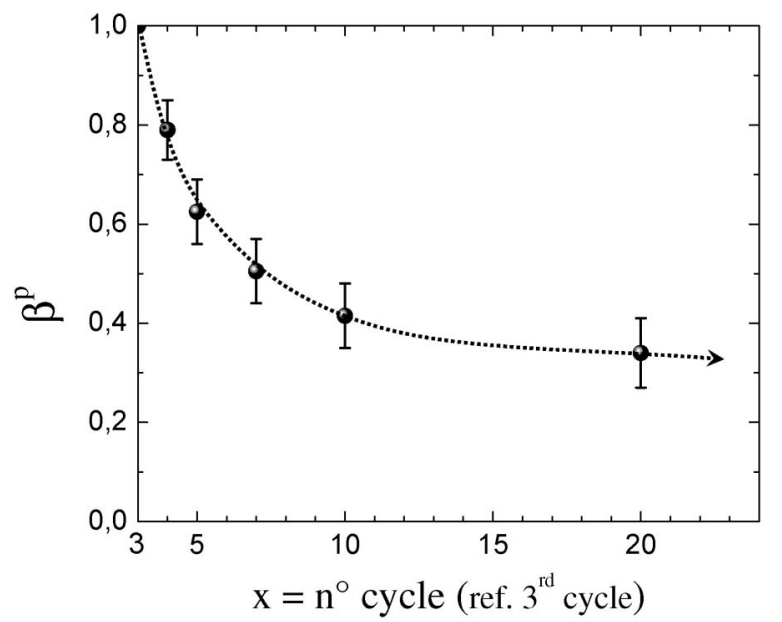

Fig. 18. Cyclic hardening parameter $\beta^{\mathrm{p}}$ as a function of cycle number (ref. 3rd cycle)

of the plastic strains increment (Fig. 16(d)) and the proportion of non-coaxial plastic strain increment (Fig. 16(c)) change within one cycle but the values remain unchanged for different cycles. In addition, the total and non-coaxial plastic strain increment amplitudes decrease with the number of cycles.

The ratio $\beta^{\mathrm{p}}$ (resp. $\beta^{\text {pnc }}$ ), defined in Eq. (24), between the norm of the total (resp. non-coaxial) plastic strain increment during the $x$ th cycle and the one during the $3 \mathrm{rd}$ cycle is presented in Fig. 17 as a function of the cycle number.

$$
\begin{aligned}
& \beta^{\mathrm{p}}=\frac{\left\|d \varepsilon_{\mathrm{x}}^{\mathrm{p}}\right\|}{\left\|d \varepsilon_{3}^{\mathrm{p}}\right\|} \\
& \beta^{\mathrm{pnc}}=\frac{\left\|d \varepsilon_{\mathrm{x}}^{\mathrm{pnc}}\right\|}{\left\|d \varepsilon_{3}^{\mathrm{pc}}\right\|}
\end{aligned}
$$

For a given cycle, both the ratios $\beta^{\mathrm{p}}$ and $\beta^{\text {pnc }}$ can be considered as nearly constant and equal: $\beta^{\mathrm{p}}=\beta^{\text {pnc }}$. This ratio, called the cyclic hardening parameter $\beta^{\mathrm{p}}$, decreases with the number of cycles (from $80 \%$ for the 4 th cycle to $30 \%$ for the 20 th cycle). Figure 18 represents the evolution of $\beta^{\mathrm{p}}$ as a function of the number of cycles. As the reference is the 3 rd cycle, the plot starts at $x=3$ with $\beta^{\mathrm{p}}=$ 1.

\section{CONCLUSIONS}

This paper describes an experimental campaign conducted in order to study the impact of the Principal Stress Axes Rotation (PSAR) on deformation characteristics. A series of drained tests on dry Hostun sand performed with a Hollow Cylinder Apparatus (HCA) called "T4C StaDy" was carried out with a continuous rotation of principal stress directions. The elastic behaviour was also investigated under these conditions with small amplitude quasi-static cycles in different directions. The focus was on the non-coaxial part of strain increment tensors (elastic and plastic) which refers to the deviation of principal stress from principal strain increment directions. The fol- lowing conclusions may be proposed:

i) A hypo-elastic model DBGS, developed at the ENTPE laboratory, is a good predictor of the evolution of the hypo-elastic tensor $M^{\mathrm{e}}$ and also elastic deformation even for important rotations of principal stress directions. A simulation of elastic strains obtained by this model provides important non-coaxial deformation. Hence, a good simulation of elastic deformation is essential to correctly estimate the non-coaxial part of plastic deformation.

ii) The tests performed, with the continuous rotation of the principal stress directions, shows huge non-coaxial plastic strain increments. Traditional plastic theory, where principal stress and principal plastic strain increment have the same direction, cannot be accepted. Therefore, a non-coaxial plastic mechanism must be considered.

iii) For a constant non-coaxial stress increment applied during tests, the non-coaxial plastic strain increment response changes continuously. No proportionality was able to be found between the norm of the noncoaxial stress increment $\left\|d s^{\mathrm{nc}}\right\|$ and the norm of the non-coaxial plastic strain increment $\left\|d \varepsilon^{\mathrm{pnc}}\right\|$.

iv) Due to device limitations, the experimental stress path is not purely non-coaxial. Indeed, the radial stress increment is not nil except for different stress levels during loading: for pure compression and extension conditions (i.e., points $A$ and $C$, Fig. 4). However, even in points $A$ and $C$ where stress increments are purely non-coaxial, the plastic strain increment has a non-negligible coaxial part. It indicates a coupling between the coaxial and non-coaxial plastic mechanisms. This coupling may be due to the difference between the principal stress axes and principal strain (calculated from the isotropic state) axes. If this is the case, it is valueless to model non-coaxial plasticity by using a proportional relationship (Eq. (16)) between the non-coaxial parts of strain and stress increments (i.e., between $d s^{\mathrm{nc}}$ and $d \varepsilon^{\mathrm{pnc}}$ ).

v) Amplitudes of plastic coaxial and non-coaxial strain increments decrease in the same proportion with the number of large amplitude cycles. Cyclic hardening is nearly the same for both coaxial and non-coaxial plastic mechanisms. In addition, even after 20 cycles, plastic deformation remains more important than elastic deformation.

\section{REFERENCES}

1) Blanc, M. (2011): Etude experimentale et modelisation du comportement des sols avec rotation d'axes principaux de contraintes, Ph.D thesis, ENTPE, University of Lyon. (in French) (to be published).

2) Di Benedetto, H., Geoffroy, H. and Sauzeat, C. (2001): Viscous and non viscous behaviour of sand obtained from hollow cylinder tests, Advanced Laboratory Stress-Strain Testing of Geomaterials, (eds. by Tatsuoka et al.), Balkema, 212-221.

3) Duttine, A. (2005): Comportement des sables et des melanges sable/argile sous sollicitations statiques et dynamiques avec et sans «rotation d'axes », Ph.D thesis, ENTPE, University of Lyon (in 
French).

4) Duttine, A., Di Benedetto, H., Pham Van Bang, D. and Ezaoui, A. (2007): Anisotropic small strain elastic properties of sands and mixture of sand-clay measured by dynamic and static methods, Soils and Foundations, 47(3), 457-472.

5) Flavigny, E., Desrues, J. and Palayer, B. (1990): Note technique: le sable d'Hostun RF, Revue Francaise de Geotechnique, 53, 67-70.

6) Gutierrez, M., Ishihara, K. and Towhata, I. (1991): Flow theory for sand during rotation of principal stress direction, Soils and Foundations, 31(4), 121-132.

7) Gutierrez, M. and Ishihara, K. (2000): Non-coaxiality and energy dissipation in granular materials, Soils and Foundations, 40(2), 49-59.

8) Hardin, B. O. and Blandford, G. E. (1989): Elasticity of particulate materials, Journal of Geotechnical Engineering, 115(6), 788-805.

9) Hight, D. W., Gens, A. and Symes, M. J. (1983): Development of a new hollow cylinder apparatus for investigating the effects of principal stress rotation in soils, Géotechnique, 33(4), 355-383.

10) Ishihara, K. and Towhata, I. (1983): Sand response to cyclic rotation of principal stress directions as induced by wave loads, Soils and Foundations, 23(4), 11-26.

11) Jardine, R. J. (1994): One perspective on the pre-failure deformation characteristics of some geomaterials, Keynote Lecture in PreFailure Deformation Characteristics of Geomaterials, (eds. by Mitachi and Miura), Balkema.
12) Miura, K., Miura, S. and Toki, S. (1986): Deformation behaviour of sand under principal axes rotation, Soils and Foundations, 26(1), 36-52.

13) Pradel, D., Ishihara, K. and Gutierrez, M. (1990): Yielding and flow of sand under principal stress axes rotation, Soils and Foundations, 30(1), 87-99.

14) Qian, J. G., Yang, J. and Huang, M. S. (2008): Three-dimensional noncoaxial plasticity modeling of shear band formation in geomaterials, Journal of Engineering Mechanics, 134(4), 322-329.

15) Rudnicki, J. W. and Rice, J. R. (1975): Conditions for the localization of deformation in pressure-sensitive dilatant materials, Journal of the Mechanics and Physics of Solids, 23, 371-394.

16) Sauzeat, C. (2003): Comportement des sols en petites et moyennes deformation, Ph.D thesis, ENTPE, University of Lyon (in French).

17) Tatsuoka, F. and Ishihara, K. (1974): Drained deformation of sand under cyclic stresses reversing direction, Soils and Foundations, 14(3), 51-65.

18) Tsutsumi, S. and Hashiguchi, K. (2005): General non-proportional loading behaviour of soils, International Journal of Plasticity, 21(10), 1941-1969.

19) $\mathrm{Yu}, \mathrm{H}$. S. and Yuan, X. (2006): On a class of non-coaxial plasticity models for granular soils, Proceedings of the Royal Society A: Mathematical, Physical and Engineering Science, 462(2067), $725-748$.

20) Yu, H. S. (2006): Plasticity and Geotechnics, Springer.

\section{APPENDIX}

For principal stress axes rotation, the sample axes $\left(\vec{e}_{\mathrm{r}}, \vec{e}_{\theta}, \vec{e}_{\mathrm{z}}\right)$ and principal stress axes $\left(\vec{e}_{\mathrm{I}}, \vec{e}_{\mathrm{II}}, \vec{e}_{\mathrm{III}}\right)$ do not coincide. An expression of the hypo-elastic tensor $M^{\mathrm{e}}$ in $\left(\vec{e}_{\mathrm{r}}, \vec{e}_{\theta}, \vec{e}_{\mathrm{z}}\right)$ axes is given below. Substituting Eqs. (11) and (12) in Eq. (10) gives the hypo-elastic tensor $M^{\mathrm{e}}$ in $\left(\vec{e}_{\mathrm{I}}, \vec{e}_{\mathrm{II}}, \vec{e}_{\mathrm{III}}\right)$ axes (Eq. (A1)).

$$
M_{\text {(I, II, III) }}^{\mathrm{e}}=\frac{1}{f(e)}\left(\begin{array}{cccc}
\frac{1}{\sigma_{\mathrm{I}}^{\mathrm{m}}} & \frac{-v_{0}}{2}\left(\frac{1}{\sigma_{\mathrm{II}}^{\mathrm{m}}}+\frac{1}{\sigma_{\mathrm{I}}^{\mathrm{m}}}\right) & \frac{-v_{0}}{2}\left(\frac{1}{\sigma_{\mathrm{III}}^{\mathrm{m}}}+\frac{1}{\sigma_{\mathrm{I}}^{\mathrm{m}}}\right) & 0 \\
\frac{-v_{0}}{2}\left(\frac{1}{\sigma_{\mathrm{I}}^{\mathrm{m}}}+\frac{1}{\sigma_{\mathrm{II}}^{\mathrm{m}}}\right) & \frac{1}{\sigma_{\mathrm{II}}^{\mathrm{m}}} & \frac{-v_{0}}{2}\left(\frac{1}{\sigma_{\mathrm{III}}^{\mathrm{m}}}+\frac{1}{\sigma_{\mathrm{I}}^{\mathrm{m}}}\right) & 0 \\
\frac{-v_{0}}{2}\left(\frac{1}{\sigma_{\mathrm{I}}^{\mathrm{m}}}+\frac{1}{\sigma_{\mathrm{III}}^{\mathrm{m}}}\right) & \frac{-v_{0}}{2}\left(\frac{1}{\sigma_{\mathrm{II}}^{\mathrm{m}}}+\frac{1}{\sigma_{\mathrm{III}}^{\mathrm{m}}}\right) & \frac{1}{\sigma_{\mathrm{III}}^{\mathrm{m}}} & 0 \\
0 & 0 & 0 & \frac{1+v_{0}}{\left(\sigma_{\mathrm{II}} \sigma_{\mathrm{III}}\right)^{\mathrm{m} / 2}}
\end{array}\right)
$$

Incremental stress tensor is expressed in $\left(\vec{e}_{\mathrm{I}}, \vec{e}_{\mathrm{II}}, \vec{e}_{\mathrm{III}}\right)$ by Eq. (A2).

$$
d \sigma_{(\mathrm{I}, \mathrm{II}, \mathrm{III})}=\mathrm{P}_{(\mathrm{I}, \mathrm{II}, \mathrm{III}) \rightarrow(\mathrm{r}, \theta, \mathrm{z})} \cdot d \sigma_{(\mathrm{r}, \theta, \mathrm{z})} \cdot \mathrm{P}_{(\mathrm{I}, \mathrm{II}, \mathrm{III}) \rightarrow(\mathrm{r}, \theta, \mathrm{z})}^{-1}
$$

with $P$ the transformation rotation matrix from $\left(\vec{e}_{\mathrm{I}}, \vec{e}_{\mathrm{II}}, \vec{e}_{\mathrm{III}}\right)$ to $\left(\vec{e}_{\mathrm{r}}, \vec{e}_{\theta}, \vec{e}_{\mathrm{z}}\right)$ :

$$
\mathrm{P}_{(\mathrm{I}, \mathrm{II}, \mathrm{III}) \rightarrow(\mathrm{r}, \theta, \mathrm{z})}=\left(\begin{array}{ccc}
1 & 0 & 0 \\
0 & \cos \left(\alpha_{\sigma}\right) & \sin \left(\alpha_{\sigma}\right) \\
0 & -\sin \left(\alpha_{\sigma}\right) & \cos \left(\alpha_{\sigma}\right)
\end{array}\right)
$$

For HCA analysis, only four terms of the strain and stress tensors are non nil. These tensors are represented by a four component vector. With this notation, the relationship (Eq. (A2)) between stress increments in $\left(\vec{e}_{\mathrm{I}}, \vec{e}_{\mathrm{II}}, \vec{e}_{\mathrm{III}}\right)$ and ( $\vec{e}_{\mathrm{r}}, \vec{e}_{\theta}$, $\vec{e}_{\mathrm{z}}$ ) becomes:

$$
d \sigma_{(\mathrm{I}, \mathrm{II}, \mathrm{III})}=\mathrm{Q} \cdot d \sigma_{(\mathrm{r}, \theta, \mathrm{z})}
$$

with

$$
\mathrm{Q}=\left(\begin{array}{cccc}
1 & 0 & 0 & 0 \\
0 & \cos ^{2}(\alpha) & \sin ^{2}(\alpha) & -\sqrt{2} \cos (\alpha) \sin (\alpha) \\
0 & \sin ^{2}(\alpha) & \cos ^{2}(\alpha) & \sqrt{2} \cos (\alpha) \sin (\alpha) \\
0 & \sqrt{2} \cos (\alpha) \sin (\alpha) & -\sqrt{2} \cos (\alpha) \sin (\alpha) & \cos ^{2}(\alpha)-\sin ^{2}(\alpha)
\end{array}\right)
$$

Then the hypo-elastic tensor $M^{\mathrm{e}}$ expression in " $\left(\vec{e}_{\mathrm{r}}, \vec{e}_{\theta}, \vec{e}_{\mathrm{z}}\right)$ base" is:

$$
M_{(\mathrm{r} \theta \mathrm{z})}^{\mathrm{e}}=\mathrm{Q}^{\mathrm{t}} \cdot M_{(\mathrm{I}, \mathrm{II}, \mathrm{III})}^{\mathrm{e}} \cdot \mathrm{Q}
$$

